Article

\title{
Effects of Length and Loop Composition on Structural Diversity and Similarity of $\left(\mathrm{G}_{3} \mathrm{TG}_{3} \mathrm{~N}_{\mathrm{m}} \mathrm{G}_{3} \mathrm{TG}_{3}\right) \mathrm{G}-\mathrm{Quadruplexes}$
}

\author{
Jie Li ${ }^{\dagger}, \mathrm{I}_{-\mathrm{Te}} \mathrm{Chu}{ }^{\dagger}{ }^{,}$, Ting-An Yeh, De-Yu Chen, Chiung-Lin Wang and Ta-Chau Chang * \\ Institute of Atomic and Molecular Sciences, Academia Sinica, Taipei 106, Taiwan; julielee0531@gmail.com (J.L.); \\ r04223204@gmail.com (I.-T.C.); tati31233@gmail.com (T.-A.Y.); ymonkeyy@gmail.com (D.-Y.C.); \\ q102081@gmail.com (C.-L.W.) \\ * Correspondence: tcchang@po.iams.sinica.edu.tw; Tel.: +886-2-23668231 \\ + These authors contributed equally to this work.
}

Received: 6 March 2020; Accepted: 9 April 2020; Published: 13 April 2020

\begin{abstract}
A G-rich sequence containing three loops to connect four G-tracts with each $\geq 2$ guanines can possibly form G-quadruplex structures. Given that all G-quadruplex structures comprise the stacking of G-quartets, the loop sequence plays a major role on their folding topology and thermal stability. Here circular dichroism, NMR, and PAGE are used to study the effect of loop length and base composition in the middle loop, and a single base difference in loop 1 and 3 on G-quadruplex formation of $\left(\mathrm{G}_{3} \mathrm{HG}_{3} \mathrm{~N}_{\mathrm{m}} \mathrm{G}_{3} \mathrm{HG}_{3}\right)$ sequences with and without flanking nucleotides, where $\mathrm{H}$ is $\mathrm{T}$, $\mathrm{A}$, or $\mathrm{C}$ and $\mathrm{N}$ is $\mathrm{T}, \mathrm{A}, \mathrm{C}$, or $\mathrm{G}$. In addition, melting curve for G-quadruplex unfolding was used to provide relatively thermal stability of G-quadruplex structure after the addition of $\mathrm{K}^{+}$overnight. We further studied the effects of $\mathrm{K}^{+}$concentration on their stability and found structural changes in several sequences. Such $\left(\mathrm{G}_{3} \mathrm{HG}_{3} \mathrm{~N}_{\mathrm{m}} \mathrm{G}_{3} \mathrm{HG}_{3}\right)$ configuration can be found in a number of native DNA sequences. The study of structural diversity and similarity from these sequences may allow us to establish the correlation between model sequences and native sequences. Moreover, several sequences upon interaction with a G-quadruplex ligand, BMVC, show similar spectral change, implying that structural similarity is crucial for drug development.
\end{abstract}

Keywords: G-quadruplex; structural diversity; structural similarity; loop length; base composition; flanking nucleotide; quadruplex-duplex junction

\section{Introduction}

A large number of guanine $(\mathrm{G})$-rich sequences are found in the human genome [1-3]. In general, G-rich sequences may adopt into various G-quadruplex (G4) structures, which depend on their sequences and lengths, loop composition, and flanking nucleotides in $\mathrm{K}^{+}$solution [4-12]. Accumulating evidence on the biological functions of G4 structures in regulating multiple cellular processes [13-18] and imaging-based studies on G4 antibodies and G4 ligands for visualizing the presence of G4s in cells [19-23] support the existence of G4 structure in vivo. Given that structural properties of G4s are critical for biomedical implication and drug development, many questions on structural variation as a result of sequence deviation are yet to be addressed. For example, under what sequence variations, one could infer rules for predicting structural similarity in G4s.

Previously, we found the structural diversity of a mitochondrial sequence mt10251 $\left(\mathrm{G}_{3} \mathrm{TG}_{3}\right.$ AGTAGTTCCCTGCTAAG $\left.\mathrm{AG}_{3}\right)$, including the coexistence of a hairpin structure and monomeric, dimeric, and tetrameric G4 structures in $20 \mathrm{mM} \mathrm{K}^{+}$solution. Moreover, a single-base mutation of mt10251 could cause significant changes in terms of structural populations and 
polymorphism [24]. Particularly, most single-base mutated sequences of mt10251 favor dimeric G4 formation in the absence of hairpin formation. This sequence contains four G-tracts with three consecutive G-bases without flanking nucleotides separated by three loops with 1, 16, and 1 nt $(1,16,1$ loop lengths). We anticipate that the dimeric $\mathrm{G} 4$ formation is mainly due to the sequences of $\mathrm{G}_{3} \mathrm{TG}_{3}$ and $G_{3} A G_{3}$ at two ends. It is of interest to examine whether the change of the middle loop length of $\left(\mathrm{G}_{3} \mathrm{HG}_{3} \mathrm{~N}_{\mathrm{m}} \mathrm{G}_{3} \mathrm{HG}_{3}\right)$ could also favor dimeric $\mathrm{G} 4$ formation, where $\mathrm{H}=\mathrm{A}, \mathrm{T}$, or $\mathrm{C}$ and $\mathrm{N}=\mathrm{A}, \mathrm{T}, \mathrm{C}, \mathrm{or} \mathrm{G}$.

The G-rich $\left(\mathrm{G}_{3} \mathrm{HG}_{3} \mathrm{~N}_{\mathrm{m}} \mathrm{G}_{3} \mathrm{HG}_{3}\right)$ configuration can be found in a number of native DNA sequences. A G-rich sequence Pu22 (TGAG $\mathrm{TG}_{3} \mathrm{TAG}_{3} \mathrm{TG}_{3} \mathrm{TAA}$ ) in the c-MYC promoter region adopts into a monomeric parallel G4 structure $[25,26]$. The deletion of $5^{\prime}$-TGA and 3'-TAA from Pu22 satisfies the category of $\left(\mathrm{G}_{3} \mathrm{HG}_{3} \mathrm{~N}_{\mathrm{m}} \mathrm{G}_{3} \mathrm{HG}_{3}\right)$. In addition, Kuryavyi and Patel reported that a G-rich human chl1 intronic sequence $\left(\mathrm{G}_{3} \mathrm{TG}_{3} \mathrm{GAAGG}_{3} \mathrm{TG}_{3} \mathrm{~T}\right)$ also adopts a monomeric $\mathrm{G} 4$ structures in $\mathrm{K}^{+}$solution [27]. Lim et al. [28] demonstrated that a G-rich sequence GTERT ( $A G G_{3} A_{3} G_{C T G} A_{3} C$ ) in the hTERT promoter can form two monomeric G4 structures. Similarly, Onel et al. [29] found that a G-rich sequence PIG4 ( $\left.\mathrm{CG}_{3} \mathrm{CG}_{3} \mathrm{AGCGCGGCGGGCG} \mathrm{CG}_{3} \mathrm{CA}\right)$ located at the upstream of the human BCL2 gene P1 promoter can form two different monomeric $\mathrm{G} 4$ structures containing a stem-loop hairpin. These findings suggest that the addition of flanking nucleotides to the G-rich sequence of $\left(\mathrm{G}_{3} \mathrm{HG}_{3} \mathrm{~N}_{\mathrm{m}} \mathrm{G}_{3} \mathrm{HG}_{3}\right)$ prefer to form monomeric G4 structure. It is curious to examine whether the deletion of the flanking nucleotides in these G-rich sequences will favor the dimeric G4 formation.

Table 1. Sequences studied in this work and their melting temperatures and conformations in the presence of 20 and $100 \mathrm{mM} \mathrm{K}^{+}$, respectively.

\begin{tabular}{|c|c|c|c|}
\hline & Sequence $\left(5^{\prime} \rightarrow 3^{\prime}\right)$ & $\begin{array}{l}\operatorname{Tm}(\mathrm{A}) \\
\left({ }^{\circ} \mathrm{C}, 20 \mathrm{mM} \mathrm{K}^{+}\right)\end{array}$ & $\begin{array}{l}\operatorname{Tm}(\mathrm{A}) \\
\left({ }^{\circ} \mathrm{C}, 100 \mathrm{mM} \mathrm{K}^{+}\right)\end{array}$ \\
\hline T16T & GGGTGGGTTGCGCAATTGCGCTTGGGTGGG & $63 \pm 1.55(\mathrm{D}, \mathrm{wM})^{\mathrm{a}}$ & $78 \pm 0.65(\mathrm{D}, \mathrm{wM})$ \\
\hline T10T & GGGTGGGTTGCATGCTTGGGTGGG & $58 \pm 1.44(\mathrm{D})$ & $73 \pm 1.12(\mathrm{D})$ \\
\hline $\mathrm{T} 4 \mathrm{~T}$ & GGGTGGGCATGGGGTGGG & $68 \pm 0.30(\mathrm{M} \rightarrow \mathrm{H})^{\mathrm{b}}$ & $84 \pm 1.56(\mathrm{M} \rightarrow \mathrm{H})$ \\
\hline $\mathrm{T} 2 \mathrm{~T}$ & GGGTGGGTAGGGTGGG & $81 \pm 0.99(\mathrm{H})$ & $>90(\mathrm{H})$ \\
\hline TTT & GGGTGGGTGGGTGGG & $62 \pm 1.70,>90$ & $78 \pm 0.92,>90$ \\
\hline T4T-1 & GGGTGGGATTAGGGTGGG & $69 \pm 0.92(\mathrm{H})$ & $85 \pm 0.77(\mathrm{H})$ \\
\hline T4T-2 & GGGTGGGCATCGGGTGGG & $68 \pm 1.61(\mathrm{H})$ & $83 \pm 0.62(\mathrm{H})$ \\
\hline T4T-3 & GGGTGGGACGTGGGTGGG & $70 \pm 0.49(\mathrm{M} \rightarrow \mathrm{H})$ & $86 \pm 1.51(\mathrm{M} \rightarrow \mathrm{H})$ \\
\hline T16T-FN & TGAGGGTGGGTTGCGCAATTGCGCTTGGGTGGGTAA & $68 \pm 0.25(\mathrm{M})$ & $77 \pm 0.49(\mathrm{M})$ \\
\hline T10T-FN & TGAGGGTGGGTTGCATGCTTGGGTGGGTAA & $68 \pm 1.02(\mathrm{M}, \mathrm{wD})$ & $77 \pm 0.62(\mathrm{M}, \mathrm{wD})$ \\
\hline T4T-FN & TGAGGGTGGGCATGGGGTGGGTAA & $68 \pm 0.44(\mathrm{M})$ & $82 \pm 0.35(\mathrm{M}, \mathrm{wD})$ \\
\hline T2T-FN & TGAGGGTGGGTAGGGTGGGTAA & $76 \pm 0.55(\mathrm{M})$ & $>90(\mathrm{M})$ \\
\hline TTT-FN & TGAGGGTGGGTGGGTGGGTAA & $>90(\mathrm{M})$ & $>90(\mathrm{M})$ \\
\hline A16T & GGGAGGGTTGCGCAATTGCGCTTGGGTGGG & $-(\mathrm{D})$ & $74 \pm 1.21(\mathrm{D})$ \\
\hline A10A & GGGAGGGTTGCATGCTTGGGAGGG & $47 \pm 1.10(\mathrm{D})$ & $62 \pm 0.38(\mathrm{D})$ \\
\hline C10C & GGGCGGGTTGCATGCTTGGGCGGG & $57 \pm 1.20(\mathrm{D})$ & $74 \pm 1.10(\mathrm{D})$ \\
\hline T10T-1 & GGGTGGGTTGCTTGCTTGGGTGGG & $61 \pm 0.60(\mathrm{D})$ & $76 \pm 0.46(\mathrm{D})$ \\
\hline A10A-1 & GGGAGGGTTGCTTGCTTGGGAGGG & $49 \pm 0.86(\mathrm{D})$ & $66 \pm 1.12(\mathrm{D})$ \\
\hline A16T-FN & TGAGGGAGGGTTGCGCAATTGCGCTTGGGTGGGTAA & $-(\mathrm{M}, \mathrm{wD})$ & $75 \pm 0.29(\mathrm{M}, \mathrm{wD})$ \\
\hline A10A-FN & TGAGGGAGGGTTGCATGCTTGGGAGGGTAA & $60 \pm 0.13(\mathrm{M}, \mathrm{wD})$ & $66 \pm 0.42(\mathrm{M}, \mathrm{D})$ \\
\hline C10C-FN & TGAGGGCGGGTTGCATGCTTGGGCGGGTAA & $65 \pm 0.42(\mathrm{M}, \mathrm{wD})$ & $74 \pm 1.16(\mathrm{M}, \mathrm{D})$ \\
\hline T10T-1-FN & TGAGGGTGGGTTGCTTGCTTGGGTGGGTAA & $67 \pm 0.28(\mathrm{M})$ & $77 \pm 0.31(\mathrm{M})$ \\
\hline A10A-1-FN & TGAGGGAGGGTTGCTTGCTTGGGAGGGTAA & $59 \pm 0.13(\mathrm{M})$ & $68 \pm 0.64(\mathrm{M})$ \\
\hline A4A-FN & TGAGGGAGGGCATGGGGAGGGTAA & $58 \pm 0.36(\mathrm{M}, \mathrm{wD})$ & $73 \pm 0.62(\mathrm{M}, \mathrm{D})$ \\
\hline C4C-FN & TGAGGGCGGGCATGGGGCGGGTAA & $68 \pm 0.48(\mathrm{M})$ & $81 \pm 0.74(\mathrm{M}, \mathrm{wD})$ \\
\hline T4T-1-FN & TGAGGGTGGGATTAGGGTGGGTAA & $67 \pm 1.63(\mathrm{M})$ & $83 \pm 0.95(\mathrm{M}, \mathrm{wD})$ \\
\hline $\mathrm{mt} 10248$ & CCAGGGTGGGAGTAGTTCCCTGCTAAGGGAGGGTAG & $58 \pm 1.06(\mathrm{M}, \mathrm{wD})$ & $67 \pm 1.08(\mathrm{D}, \mathrm{wM})$ \\
\hline 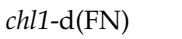 & GGGTGGGGAAGGGGTGGG & $71 \pm 0.60$ & $63 \pm 0.39,84 \pm 0.61(\mathrm{M})$ \\
\hline GTERT-d(FN) & GGGAGGGGCTGGGAGGG & $70 \pm 0.66$ & $84 \pm 1.48(\mathrm{M} \rightarrow \mathrm{H})$ \\
\hline PIG4-d(FN) & GGGCGGGAGCGCGGCGGGCGGGCGGG & - & $82 \pm 1.52(\mathrm{D})$ \\
\hline
\end{tabular}

${ }^{a}$ M: monomer, D: dimer, H: high-order, w: weak. ${ }^{b} \mathrm{M} \rightarrow \mathrm{D}$ : monomer converts to dimer as a function of time. 
In this work, we use nuclear magnetic resonance (NMR) for identifying G4 formation, circular dichroism (CD) for distinguishing parallel and nonparallel G4 structures, and polyacrylamide gel electrophoresis (PAGE) for classifying monomeric, dimeric, and tetrameric G4 formation of a number of G-rich sequences in $\mathrm{K}^{+}$solution. Particularly, imino proton NMR spectra can provide distinct peaks near 13 ppm for duplex signals of G-base, near 13.5 ppm for duplex signals of T-base, and 10-12.5 ppm for G4 signals [30]. Such imino proton NMR signals are important in the comparison of structural diversity and similarity of these G-rich sequences. Since the $100 \mu \mathrm{M}$ DNA concentration is normally used to obtain imino proton NMR spectra, this DNA concentration is applied for all the experiments in this work. We first examine the loop effect, particularly, on the formation of dimeric $\mathrm{G} 4$ structure by changing the middle loop size in the G-rich sequence of $\left(\mathrm{G}_{3} \mathrm{HG}_{3} \mathrm{~N}_{\mathrm{m}} \mathrm{G}_{3} \mathrm{HG}_{3}\right)$. For simplicity, we tentatively label each sequence by using the characters of the three loops, such as T16T for $\mathrm{G}_{3} \mathrm{TG}_{3}$ TTGCGCAATTGCGCTTG ${ }_{3} \mathrm{TG}_{3}$. Considering the similarity between $\left(\mathrm{G}_{3} \mathrm{TG}_{3} \mathrm{TAG}_{3} \mathrm{TG}_{3}\right)$ and (TGAG $\left.\mathrm{TG}_{3} \mathrm{TAG}_{3} \mathrm{TG}_{3} \mathrm{TAA}\right)$, we further study the $\left(\mathrm{G}_{3} \mathrm{HG}_{3} \mathrm{~N}_{\mathrm{m}} \mathrm{G}_{3} \mathrm{HG}_{3}\right)$ sequences with the addition of flanking nucleotides (FN) at both ends of $5^{\prime}$-TGA and TAA-3' to examine whether they form monomeric G4 structures. The sequences studied in this work are listed in Table 1. In addition, CD melting is used to define quadruplex stability and $\mathrm{G} 4$ binding ligand is applied to examine structural diversity and similarity. Since such G-rich sequences $\left(\mathrm{G}_{3} \mathrm{HG}_{3} \mathrm{~N}_{\mathrm{m}} \mathrm{G}_{3} \mathrm{HG}_{3}\right)$ are found in a number of native DNA, it is important to explore if there are some common features of their G4 structures with and without the flanking nucleotides. Figure 1 shows the proposed G4 topologies in this work.

(a)

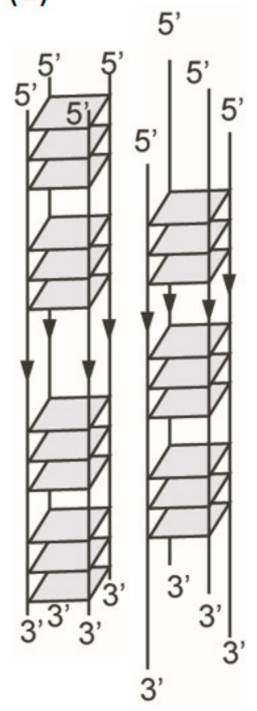

(b)

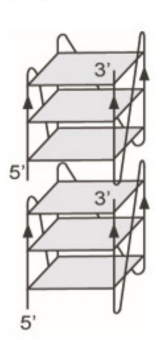

(f)

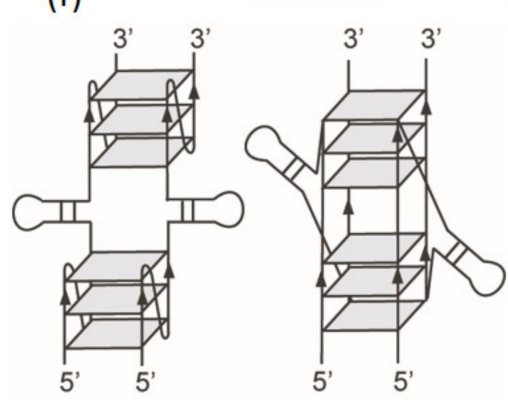

(c)

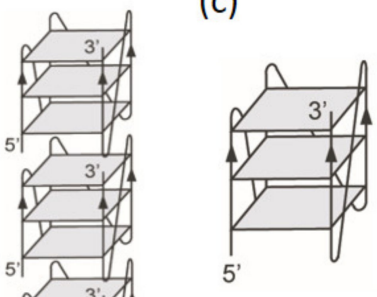

(g)

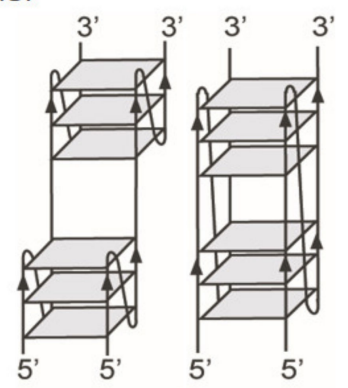

(e)

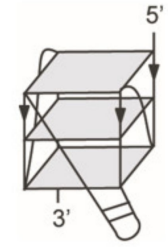

(h)
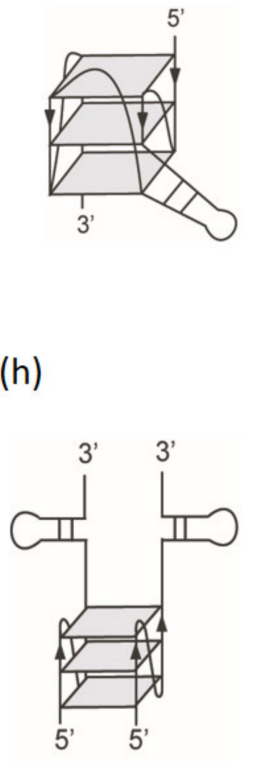

Figure 1. Proposed G4 topologies in this study. (a) parallel tetramers, (b) stacking of parallel monomers, (c) parallel monomer, (d) parallel quadruplex-duplex monomer, (e) unprecedented quadruplex-duplex monomer, (f) parallel quadruplex-duplex dimers, (g) parallel quadruplex dimers, (h) quadruplex-duplex dimer with one quadruplex.

\section{Results}

\subsection{Effect of Loop Length on $G 4$ Formation of $\left(G_{3} T G_{3} N_{m} G_{3} T G_{3}\right)$ Sequences}

The CD spectra of T16T, T10T, T2T, and TTT sequences showed similar intensity at a major $265 \mathrm{~nm}$ band after $1 \mathrm{~h}$ and overnight addition of $100 \mathrm{mM} \mathrm{K}^{+}$, implying that the growth of parallel G4 structure is predominant for these G-rich sequences (Figure 2). NMR spectra of each sequence were also similar after $1 \mathrm{~h}$ and overnight addition of $100 \mathrm{mM} \mathrm{K}^{+}$. Particularly, similar spectral patterns were detected 
in the region of 10-12 ppm between T16T and T10T (Figure 2). It is likely that T16T and T10T form similar type of G4 structure, except the coexistence of duplex formation in T16T based on the presence of imino proton signals near $13 \mathrm{ppm}$. The detection of imino proton NMR signals in the region of 12.5-14.0 ppm is due to Watson-Crick (WC) hydrogen bond. Of interest was that the CD spectra of T4T showed spectral change from a major $265 \mathrm{~nm}$ band together with a minor $290 \mathrm{~nm}$ band to a single $265 \mathrm{~nm}$ band after the addition of $100 \mathrm{mM} \mathrm{K}^{+}$from $1 \mathrm{~h}$ to overnight (Figure 2). Spectral change was also detected in its imino proton NMR spectra. Of interest is that the PAGE results of T16T, T10T, T2T, and TTT sequences showed a predominant band of multimeric G4 formation after $1 \mathrm{~h}$ and overnight addition of $100 \mathrm{mM} \mathrm{K}^{+}$, while the PAGE assays of T4T showed the change from a band of monomeric G4 formation to a major band of multimeric G4 formation after the addition of $100 \mathrm{mM} \mathrm{K}^{+}$from $1 \mathrm{~h}$ to overnight. Similar results on these sequences were also observed after the addition of $20 \mathrm{mM} \mathrm{K}^{+}$ (data not shown). In this work, the same $100 \mu \mathrm{M}$ DNA concentration was used in CD, NMR, and PAGE experiments. Our findings suggested that these $\left(\mathrm{G}_{3} \mathrm{TG}_{3} \mathrm{~N}_{\mathrm{m}} \mathrm{G}_{3} \mathrm{TG}_{3}\right)$ sequences without flanking nucleotides favor multimeric G4 formation. Notably, the similar gel migrations of TTT (15-mer) and T10T (24-mer) in PAGE suggested that T10T is likely due to a dimer, while TTT is probably due to a trimer or even a tetramer.
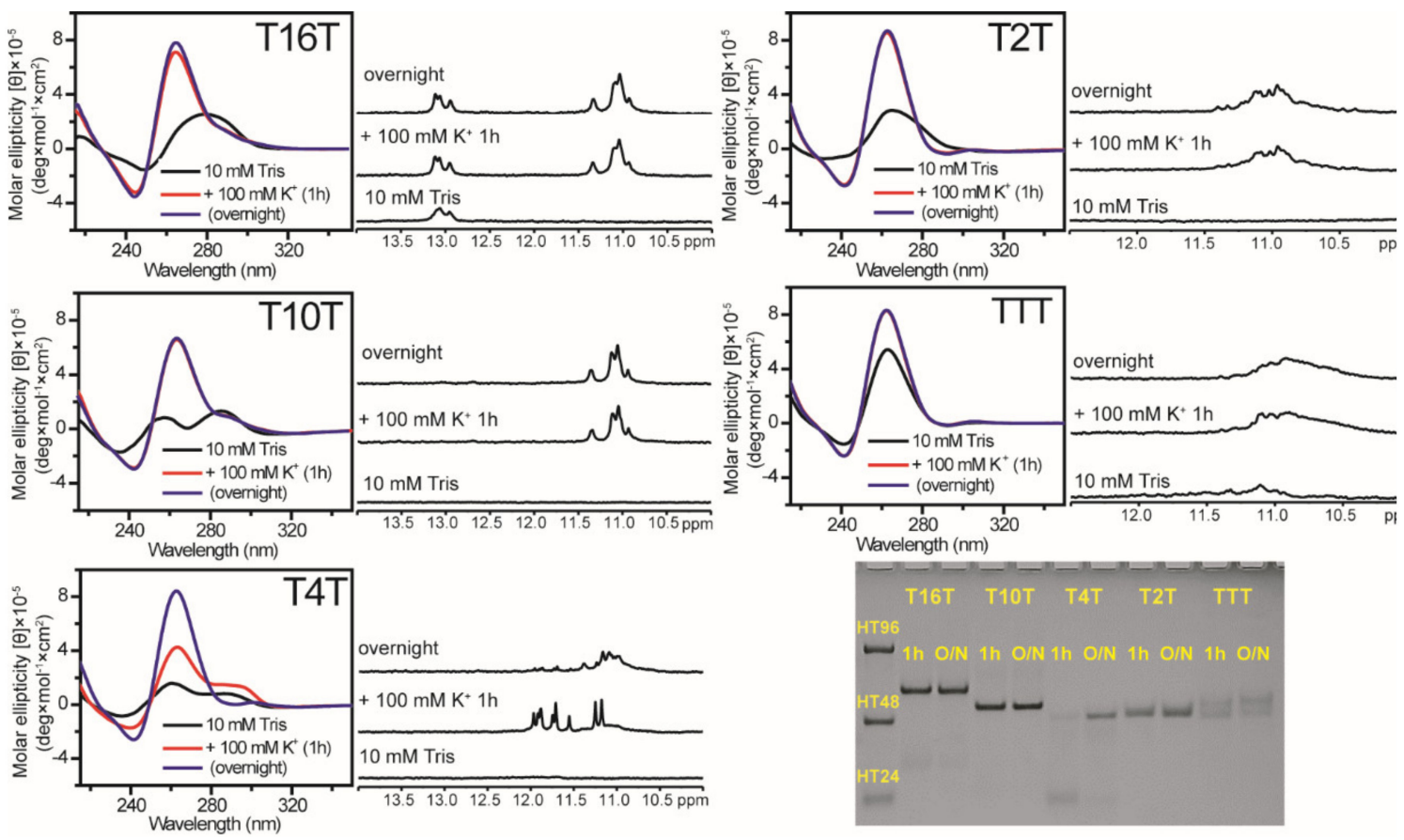

Figure 2. The effect of loop length on $\mathrm{G} 4$ formation of $\left(\mathrm{G}_{3} \mathrm{TG}_{3} \mathrm{~N}_{\mathrm{m}} \mathrm{G}_{3} \mathrm{TG}_{3}\right)$ sequences. $\mathrm{CD}$ and $\mathrm{NMR}$ spectra of T16T, T10T, T4T, T2T, and TTT in $10 \mathrm{mM}$ Tris and after $1 \mathrm{~h}$ and overnight $(\mathrm{O} / \mathrm{N})$ addition of $100 \mathrm{mM} \mathrm{K}^{+}$together with their PAGE assays of marker bands of HT24 $\left(\mathrm{T}_{2} \mathrm{AG}_{3}\right)_{4}, \mathrm{HT} 48\left(\mathrm{~T}_{2} \mathrm{AG}_{3}\right)_{8}$, and HT96 $\left(\mathrm{T}_{2} \mathrm{AG}_{3}\right)_{16}$ (lane 1 ) and each sequence after $1 \mathrm{~h}$ and $\mathrm{O} / \mathrm{N}$ addition of $100 \mathrm{mM} \mathrm{K} \mathrm{K}^{+}$for T16T, T10T, T4T, T2T, and TTT. The same DNA concentration of $100 \mu \mathrm{M}$ was used in the experiments of CD, NMR and PAGE of this work.

\subsection{Effect of Base Composition in the Middle Loop on $G 4$ Formation of $\left(G_{3} T G_{3} N_{4} G_{3} T G_{3}\right)$ Sequences}

Here the spectral change from a monomeric G4 structure to a multimeric G4 structure was clearly detected in T4T after the addition of $100 \mathrm{mM} \mathrm{K}^{+}$, while the monomeric G4 structure was negligible for T16T, T10T, T2T, and TTT sequences. To examine whether such structural conversion can be affected by the change of middle loop sequence of $\mathrm{T} 4 \mathrm{~T}$, we studied three more sequences by changing the middle loop bases, ATTA for T4T-1, CATC for T4T-2, and ACGT for T4T-3. Their CD and NMR results showed that the spectral change was also detected in T4T-3, but not found in T4T-1 and T4T-2 after the addition of $100 \mathrm{mM} \mathrm{K}^{+}$(Figure 3). In addition, the PAGE assays of T4T-3 supported the structural change from 
monomeric G4 formation to multimeric G4 formation after the addition of $100 \mathrm{mM} \mathrm{K}^{+}$from $1 \mathrm{~h}$ to overnight. However, the details of structural conversion detected in T4T and T4T-3, but not in T4T-1 and T4T-2 deserve further study. Here their imino proton NMR spectra showed different spectral patterns, implying that their folding patterns depend upon base composition in the middle loop.
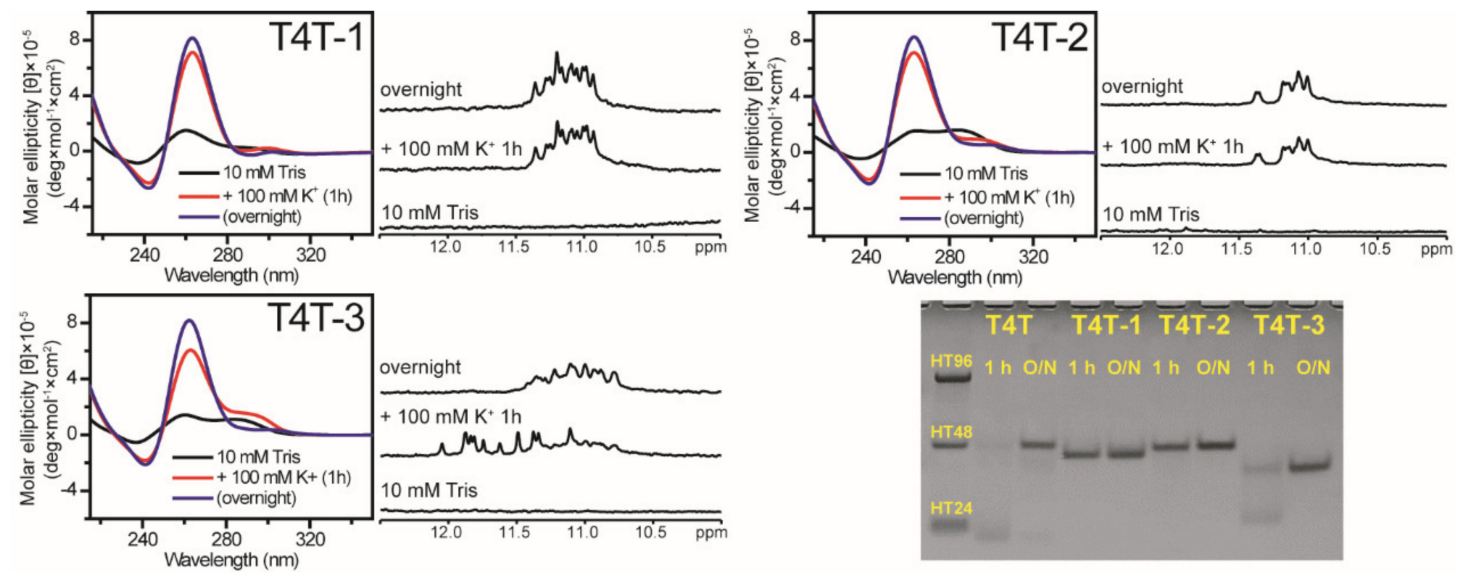

Figure 3. The effect of middle loop base on $G 4$ formation of $\left(\mathrm{G}_{3} \mathrm{TG}_{3} \mathrm{~N}_{4} \mathrm{G}_{3} \mathrm{TG} \mathrm{G}_{3}\right)$ sequences. $\mathrm{CD}$ and NMR spectra of T4T-1, T4T-2, and T4T-3 in $10 \mathrm{mM}$ Tris and after $1 \mathrm{~h}$ and overnight $(\mathrm{O} / \mathrm{N})$ addition of $100 \mathrm{mM} \mathrm{K}^{+}$together with their PAGE assays of marker bands of HT24 $\left(\mathrm{T}_{2} \mathrm{AG}_{3}\right)_{4}, \mathrm{HT} 48\left(\mathrm{~T}_{2} \mathrm{AG}_{3}\right)_{8}$, and HT96 $\left(\mathrm{T}_{2} \mathrm{AG}_{3}\right)_{16}$ (lane 1 ) and each sequence after $1 \mathrm{~h}$ and $\mathrm{O} / \mathrm{N}$ addition of $100 \mathrm{mM} \mathrm{K}{ }^{+}$for T4T, T4T-1, T4T-2, and T4T-3. The same DNA concentration of $100 \mu \mathrm{M}$ was used in the experiments of CD, NMR and PAGE of this work.

\subsection{Effect of Flanking Nucleotides on $G 4$ Formation of $\left(G_{3} T G_{3} N_{m} G_{3} T G_{3}\right)-F N$ Sequences}

Given that Pu22 forms monomeric parallel G4 structure in $\mathrm{K}^{+}$solution, we further studied the above G-rich sequences with the addition of flanking nucleotides (FN) at both ends of $5^{\prime}$-TGA and TAA-3' (Table 1, Figure 4). Their CD spectra showed a positive band near $265 \mathrm{~nm}$ together with a negative band near $245 \mathrm{~nm}$ after the addition of $100 \mathrm{mM} \mathrm{K}{ }^{+}$, suggesting that they all form parallel G4 structures. The NMR spectra of T16T-FN and T10T-FN showed almost identical imino proton signals in the region of 10-12.5 ppm, which differ from similar spectral patterns detected in T4T-FN and T2T-FN. However, the imino proton signals detected in the region of $12.5-14.0$ ppm in T10T-FN were very different from that in T16T-FN. Of interest was the fact that the imino proton signals detected in the region of 12.5-14.0 ppm in T10T-FN are not detected in T10T after the addition of $100 \mathrm{mM} \mathrm{K}^{+}$. The PAGE results showed a predominantly monomeric band for all of them. According to the gel migration, a weak dimeric band was detected in the gel migration of T10T-FN (30-mer) and T4T-FN (24-mer) in $100 \mathrm{mM} \mathrm{K}^{+}$solution. Notably, such dimeric band was negligible in the gel migration in $20 \mathrm{mM} \mathrm{K}^{+}$solution. In addition, the imino proton signals in the region of $12.5-14.0 \mathrm{ppm}$ in T10T-FN were not detected in $20 \mathrm{mM} \mathrm{K}^{+}$solution (data not shown). Our results illustrated that these $\left(\mathrm{G}_{3} \mathrm{TG}_{3} \mathrm{~N}_{\mathrm{m}} \mathrm{G}_{3} \mathrm{TG}_{3}\right)$-FN sequences form predominantly monomeric $\mathrm{G} 4$ structures even after the addition of $100 \mathrm{mM} \mathrm{K}^{+}$. Furthermore, time-dependent CD studies showed that the growth of $265 \mathrm{~nm}$ CD signal of monomeric $G 4$ formation for $\left(\mathrm{G}_{3} \mathrm{TG}_{3} \mathrm{~N}_{\mathrm{m}} \mathrm{G}_{3} \mathrm{TG}_{3}\right)$-FN sequences is more rapid than that of multimeric $\mathrm{G} 4$ formation for $\left(\mathrm{G}_{3} \mathrm{TG}_{3} \mathrm{~N}_{\mathrm{m}} \mathrm{G}_{3} \mathrm{TG}_{3}\right)$ sequences after the addition of $20 \mathrm{mM} \mathrm{K}^{+}$(Figure S1). 

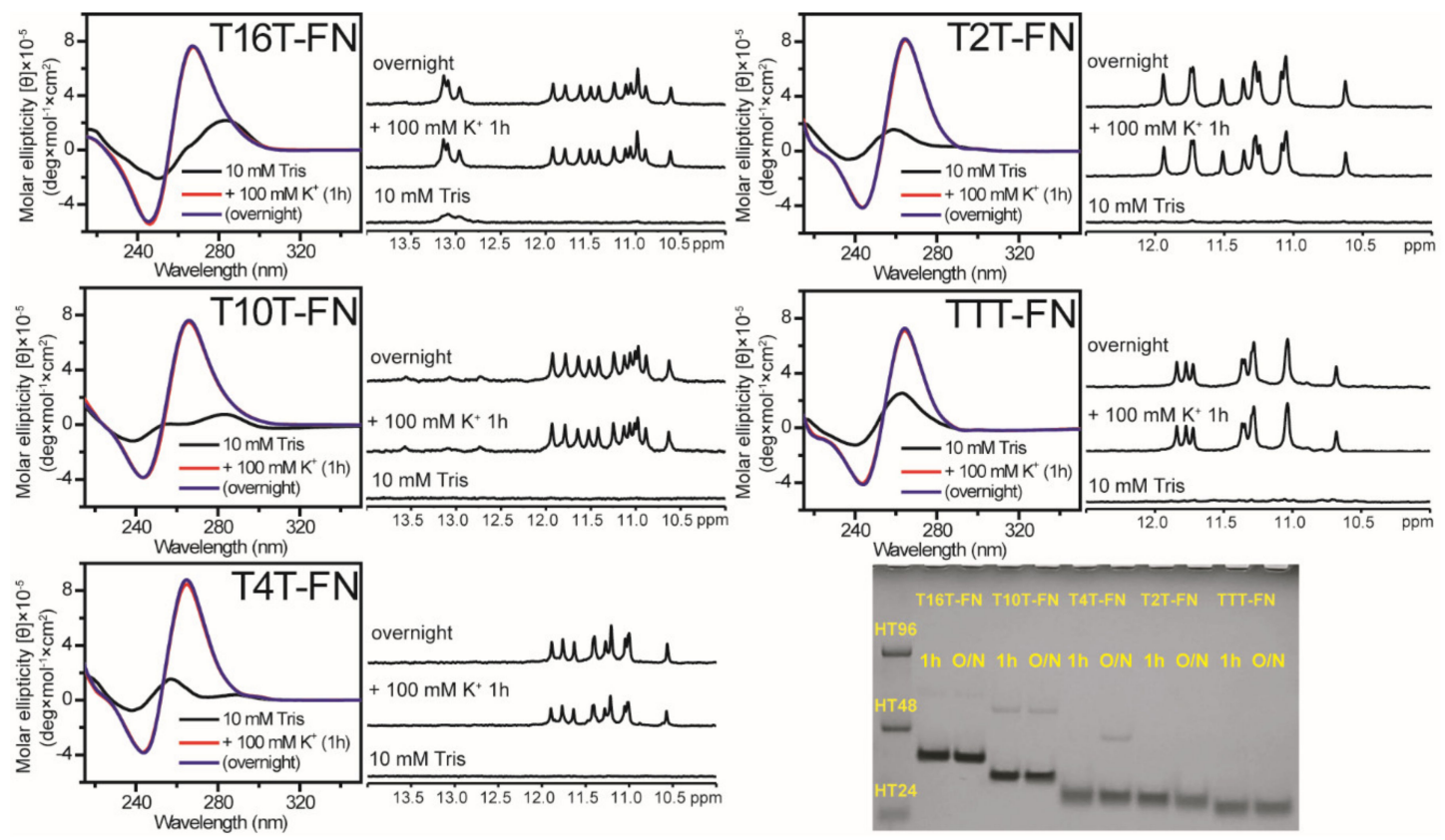

Figure 4. The effect of flanking nucleotides on $\mathrm{G} 4$ formation of $\left(\mathrm{G}_{3} \mathrm{TG}_{3} \mathrm{~N}_{\mathrm{m}} \mathrm{G}_{3} \mathrm{TG} \mathrm{G}_{3}\right)-\mathrm{FN}$ sequences. $\mathrm{CD}$ and NMR spectra of T16T-FN, T10T-FN, T4T-FN, T2T-FN, and TTT-FN in $10 \mathrm{mM}$ Tris and after $1 \mathrm{~h}$ and overnight $(\mathrm{O} / \mathrm{N})$ addition of $100 \mathrm{mM} \mathrm{K}^{+}$together with their PAGE assays of marker bands of $\mathrm{HT} 24\left(\mathrm{~T}_{2} \mathrm{AG}_{3}\right)_{4}, \mathrm{HT} 48\left(\mathrm{~T}_{2} \mathrm{AG}_{3}\right)_{8}$, and HT96 $\left(\mathrm{T}_{2} \mathrm{AG}_{3}\right)_{16}$ and each sequence after $1 \mathrm{~h}$ and $\mathrm{O} / \mathrm{N}$ addition of $100 \mathrm{mM} \mathrm{K}^{+}$for T16T-FN, T10T-FN, T4T-FN, T2T-FN, and TTT-FN. The same DNA concentration of 100 $\mu \mathrm{M}$ was used in the experiments of $\mathrm{CD}, \mathrm{NMR}$ and PAGE of this work.

\subsection{Effect of a Single Base Difference in Loop 1 and 3 on G4 Formation of $\left(G_{3} H_{G_{3}} N_{m} G_{3} H G_{3}\right)$-FN Sequences}

Given that T16T and T10T sequences showed almost identical CD and NMR spectral patterns, we further examined how a single base modification in loop 1 and 3 can affect the G4 structure. The PAGE results of $\mathrm{A} 16 \mathrm{~T}, \mathrm{~A} 10 \mathrm{~A}$, and $\mathrm{C} 10 \mathrm{C}$ sequences showed a predominant band of dimeric formation after the addition of $100 \mathrm{mM} \mathrm{K}^{+}$(Figure S2). Of interest was that the CD and NMR spectra of these sequences showed almost identical spectral patterns in the 10-12.5 ppm region, suggesting that such change has no appreciable effect on their G4 structures. Similar results were also observed after the addition of $20 \mathrm{mM} \mathrm{K}^{+}$(data not shown).

The imino proton NMR spectra of A16T-FN, A10A-FN, and C10C-FN showed almost identical signals in the region of $10-12.5 \mathrm{ppm}$ in $20 \mathrm{mM} \mathrm{K}^{+}$solution (Figure $5 \mathrm{a}$ ) and $100 \mathrm{mM} \mathrm{K}^{+}$solution (Figure S3). However, the imino proton signals in the region of 12.5-14.0 ppm of A10A-FN and C10C-FN were also detected in $100 \mathrm{mM} \mathrm{K}^{+}$solution, but not detected in $20 \mathrm{mM} \mathrm{K}^{+}$solution. The CD spectra suggested that they all form parallel type of G4 structures (data not shown). Of interest was the fact that the PAGE results of A10A-FN and C10C-FN showed a predominantly monomeric band in $20 \mathrm{mM} \mathrm{K}^{+}$solution (Figure 5a), but a marked increase in dimeric population in $100 \mathrm{mM} \mathrm{K}^{+}$solution (Figure S3). We found no appreciable change in the imino proton NMR signals in the 10.0-12.5 ppm region of A10A-FN and C10C-FN, even though there is marked increase in dimeric population in $100 \mathrm{mM} \mathrm{K}^{+}$solution. Nevertheless, our results suggested that a single-base difference of $\mathrm{A}, \mathrm{T}$, and $\mathrm{C}$ in loop 1 and loop 3 of $\mathrm{H} 10 \mathrm{H}-\mathrm{FN}$ sequences makes no appreciable change on their monomeric G4 structures. 
(a)

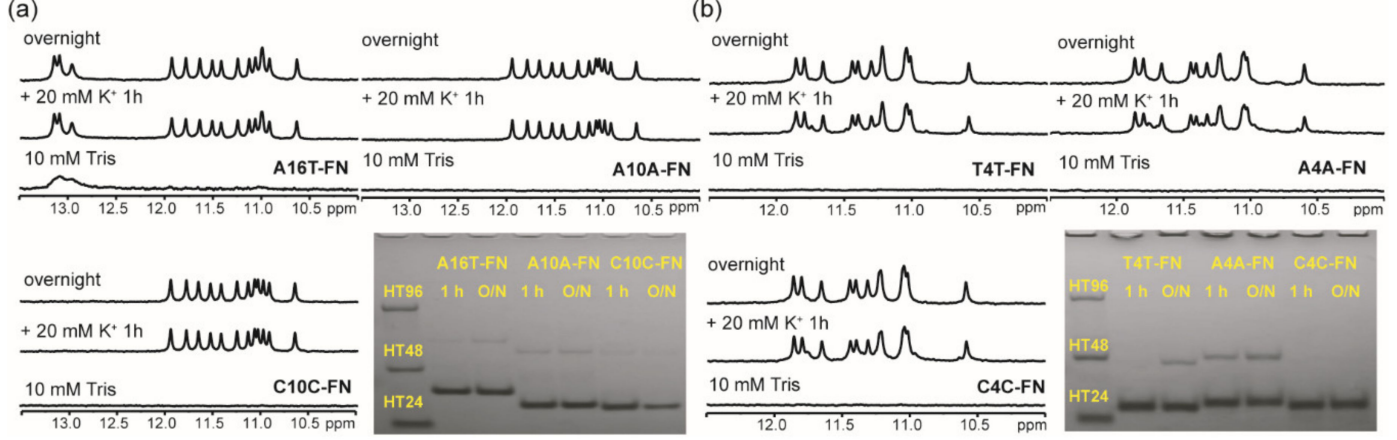

Figure 5. The effect of a single base change in loop 1 and 3 on $\mathrm{G} 4$ formation of $\left(\mathrm{G}_{3} \mathrm{HG}_{3} \mathrm{~N}_{\mathrm{m}} \mathrm{G}_{3} \mathrm{HG}_{3}\right)-\mathrm{FN}$ sequences. (a) NMR spectra of A16T-FN, A10A-FN, and C10C-FN in $10 \mathrm{mM}$ Tris and after $1 \mathrm{~h}$ and overnight $(\mathrm{O} / \mathrm{N})$ addition of $20 \mathrm{mM} \mathrm{K}^{+}$together with their PAGE assays of marker bands of HT24 $\left(\mathrm{T}_{2} \mathrm{AG}_{3}\right)_{4}, \mathrm{HT} 48\left(\mathrm{~T}_{2} \mathrm{AG}_{3}\right)_{8}$, and $\mathrm{HT} 96\left(\mathrm{~T}_{2} \mathrm{AG}_{3}\right)_{16}$ and each sequence after $1 \mathrm{~h}$ and $\mathrm{O} / \mathrm{N}$ addition of $20 \mathrm{mM}$ $\mathrm{K}^{+}$for A16T-FN, A10A-FN, and C10C-FN. (b) NMR spectra of T4T-FN, A4A-FN, and C4C-FN in $10 \mathrm{mM}$ Tris and after $1 \mathrm{~h}$ and $\mathrm{O} / \mathrm{N}$ addition of $20 \mathrm{mM} \mathrm{K}^{+}$together with their PAGE assays of marker bands of HT24 $\left(\mathrm{T}_{2} \mathrm{AG}_{3}\right)_{4}, \mathrm{HT} 48\left(\mathrm{~T}_{2} \mathrm{AG}_{3}\right)_{8}$, and HT96 $\left(\mathrm{T}_{2} \mathrm{AG}_{3}\right)_{16}$ and each sequence after $1 \mathrm{~h}$ and $\mathrm{O} / \mathrm{N}$ addition of $20 \mathrm{mM} \mathrm{K}^{+}$for T4T-FN, A4A-FN, and C4C-FN. The same DNA concentration of $100 \mu \mathrm{M}$ was used in the experiments of NMR and PAGE of this work.

In addition, the imino proton NMR spectra of T4T-FN, A4A-FN, and C4C-FN also showed almost identical signals in the region of $10-12.5 \mathrm{ppm}$ in $20 \mathrm{mM} \mathrm{K} \mathrm{K}^{+}$solution (Figure $5 \mathrm{~b}$ ). The PAGE results supported that they favor to form monomeric G4 structure. The CD spectra suggested that they all form parallel type of G4 structure (data not shown). In addition, their NMR spectral patterns were also similar after $1 \mathrm{~h}$ addition of $100 \mathrm{mM} \mathrm{K}^{+}$. However, the imino proton NMR signals of A4A-FN showed some difference from that of T4T-FN and C4C-FN after overnight addition of $100 \mathrm{mM} \mathrm{K}^{+}$(Figure S4). Of interest was that the PAGE assays of A4A-FN showed a large change from monomeric population to dimeric population as a function of time in $100 \mathrm{mM} \mathrm{K}^{+}$solution. It is not clear why such change is less detected in T4T-FN and not detected in C4C-FN. Here the imino proton NMR spectra also suggested that a single-base difference of $A$, $T$, and $C$ in loop 1 and loop 3 in $\left(\mathrm{G}_{3} \mathrm{HG}_{3} \mathrm{~N}_{4} \mathrm{G}_{3} \mathrm{HG}_{3}\right)$-FN sequences has no appreciable effect on their monomeric G4 structures.

\subsection{Effect on G4 Formation of Native G-Rich Sequences without Flanking Nucleotides}

In addition to Pu22, a number of native $G$-rich sequences containing $\left(\mathrm{G}_{3} \mathrm{HG}_{3} \mathrm{~N}_{\mathrm{m}} \mathrm{G}_{3} \mathrm{HG}_{3}\right)$ sequences with flanking nucleotides, such as chl1 [27], GTERT [28], and PIG4 [29] were previously studied by NMR, and they all favored to form monomeric G4 structures. Here we examined whether these sequences without flanking nucleotides favor to form multimeric G4 structures. The CD spectra showed a major growth of the $265 \mathrm{~nm}$ band together with a minor growth of the $295 \mathrm{~nm}$ band for chl1-d(FN) and GTERT-d(FN) and a growth of the $265 \mathrm{~nm}$ band for PIG4-d(FN) after $1 \mathrm{~h}$ addition of $100 \mathrm{mM} \mathrm{K}^{+}$. After overnight addition of $100 \mathrm{mM} \mathrm{K}^{+}$, the $265 \mathrm{~nm}$ band kept growth, while the $295 \mathrm{~nm}$ band decreased for chl1-d(FN) and GTERT-d(FN) (Figure 6). In addition, NMR spectra showed fine imino proton signals for chl1-d(FN), spectral change from fine signals to broad band for GTERT-d(FN), and broad band for PIG4-d(FN) after the addition of $100 \mathrm{mM} \mathrm{K} \mathrm{K}^{+}$(Figure 6). In addition, PAGE assays showed a predominantly monomeric band for chl1-d(FN), conformational change from a monomeric band to a multimeric band for GTERT-d(FN) (17-mer), and a major dimeric band for PIG4-d(FN) (26-mer) after the addition of $100 \mathrm{mM} \mathrm{K}^{+}$(Figure 6). These findings indicated that PIG4-d(FN) and GTERT-d(FN) also favor to form multimeric G4 structures. However, chl1-d(FN) forms monomeric G4 structure after the addition of $100 \mathrm{mM} \mathrm{K}^{+}$. 

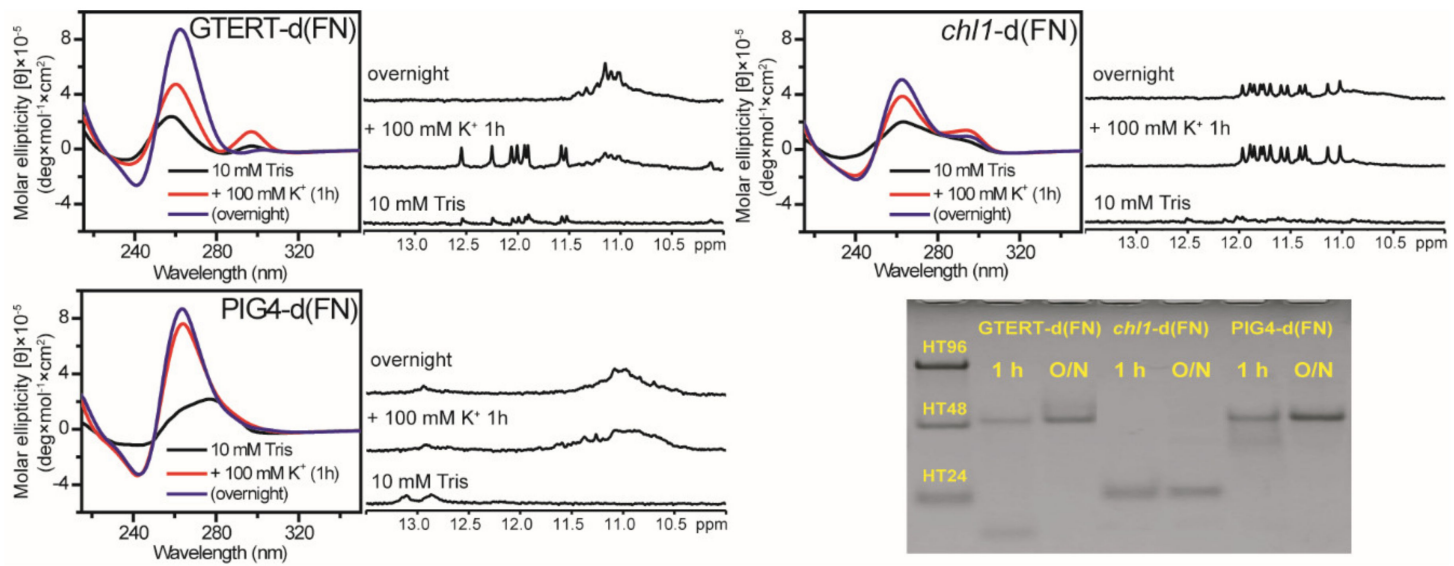

Figure 6. The Effect on G4 formation of native G-rich sequences without flanking nucleotides. CD and NMR spectra of GTERT-d(FN), PIG4-d(FN), and chl1-d(FN) in $10 \mathrm{mM}$ Tris and after $1 \mathrm{~h}$ and overnight $(\mathrm{O} / \mathrm{N})$ addition of $100 \mathrm{mM} \mathrm{K}{ }^{+}$together with their PAGE assays of marker bands of HT24 $\left(\mathrm{T}_{2} \mathrm{AG}_{3}\right)_{4}$, HT48 $\left(\mathrm{T}_{2} \mathrm{AG}_{3}\right)_{8}$, and HT96 $\left(\mathrm{T}_{2} \mathrm{AG}_{3}\right)_{16}$ and each sequence after $1 \mathrm{~h}$ and $\mathrm{O} / \mathrm{N}$ addition of $100 \mathrm{mM} \mathrm{K}^{+}$for GTERT-d(FN), chl1-d(FN), and PIG4-d(FN). The same DNA concentration of $100 \mu \mathrm{M}$ was used in the experiments of CD, NMR and PAGE of this work.

The question is why chl1- $\mathrm{d}(\mathrm{FN})$ does not favor multimeric G4 formation after the addition of $100 \mathrm{mM} \mathrm{K}^{+}$. This is probably due to four consecutive $\mathrm{G}$ bases in the second and third G-tracts of chl1-d(FN) because the flexibility of four consecutive $\mathrm{G}$ bases can change a single T-base in loop 1 and in loop 3 as $\left(\mathrm{G}_{3} \mathrm{TG}_{3} \mathrm{GAAGG}_{3} \underline{\mathrm{TG}}_{3}\right)$ to a TG in loop 1 and a GT in loop 3 as $\left(\mathrm{G}_{3} \underline{\mathrm{TG}} \mathrm{G}_{3} A \mathrm{AG}_{3} \mathrm{GTG}_{3}\right)$. We further

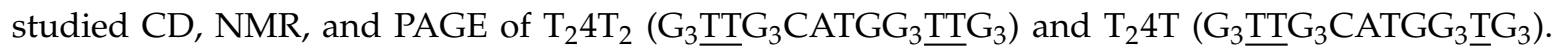
The results showed that these two sequences formed monomeric $\mathrm{G} 4$ structures instead of multimeric G4 structures after the addition of $100 \mathrm{mM} \mathrm{K}^{+}$(Figure S5). Thus, it is likely that G-rich sequences containing $\left(\mathrm{G}_{3} \mathrm{HG}_{3} \mathrm{~N}_{\mathrm{m}} \mathrm{G}_{3} \mathrm{HG}_{3}\right)$ without four consecutive G-bases favor multimeric $\mathrm{G} 4$ formation.

\subsection{Effect of Flanking Nucleotides on G4 Formation of mt10251-FN (mt10248)}

Given that the third G-tract of G24-G26 may be involved in hairpin formation of mt10251 in $10 \mathrm{mM}$ Tris [24], we examined whether a native sequence, CCAG $_{3}$ TG $_{3}$ AGTAGTTCCCTG CTAAG ${ }_{3}$ G $_{3}$ TAG (mt10248), which simply adds native flanking nucleotides to the mt10251 sequence with 5' -CCA and TAG-3' at two ends, could form a monomeric G4 structure. The NMR spectra of mt10248 showed very weak signals near 13 ppm in $10 \mathrm{mM}$ Tris, implying that hairpin formation is almost negligible. However, the imino proton signals near 13 ppm was detected right after the addition of $20 \mathrm{mM} \mathrm{K}^{+}$ and then decreased slowly, whereas imino proton signals in the region of 10-12.5 ppm were detected later and increased slowly (Figure 7a). Of interest is that both signals near $13 \mathrm{ppm}$ and in the region of 10-12.5 ppm were detected right after the addition of $100 \mathrm{mM} \mathrm{K}^{+}$(Figure $7 \mathrm{~b}$ ). The increase of positive CD bands at $265 \mathrm{~nm}$ is a typical CD pattern for parallel G4 structures. In addition, CD spectra showed that the increase of the $265 \mathrm{~nm}$ band intensity is very slow after the addition of $20 \mathrm{mM} \mathrm{K}^{+}$and relatively faster after the addition of $100 \mathrm{mM} \mathrm{K}^{+}$(Figure 7a,b). Further study of time-dependent CD signal at 265 nm showed that the arising time about $570 \mathrm{~min}$ after the addition of $20 \mathrm{mM} \mathrm{K} \mathrm{K}^{+}$is much longer than the arising time about $47 \mathrm{~min}$ after the addition of $100 \mathrm{mM} \mathrm{K}^{+}$(Figure 7c). PAGE results suggested that only small portion of mt10248 formed monomeric G4 structure after the addition of $20 \mathrm{mM} \mathrm{K}^{+}$overnight. Of importance is the fact that a small portion of mt10248 remains in monomeric G4 structure, while most of mt10248 forms a major component of dimeric G4 structure after the addition of $100 \mathrm{mM} \mathrm{K}^{+}$ overnight (Figure $7 \mathrm{~d}$ ). The studies of $\mathrm{mt10248}$ illustrated that low $\mathrm{K}^{+}$concentrations favor monomeric $\mathrm{G} 4$ formation, while high $\mathrm{K}^{+}$concentrations favor dimeric $\mathrm{G} 4$ formation. These findings demonstrated the effect of $\mathrm{K}^{+}$concentration that could cause marked changes in terms of structural populations and 
polymorphism. Although a G-tract in mt10248 could be involved in hairpin formation, its monomeric G4 structure was co-existed and detected after the addition of $\mathrm{K}^{+}$.

(a)

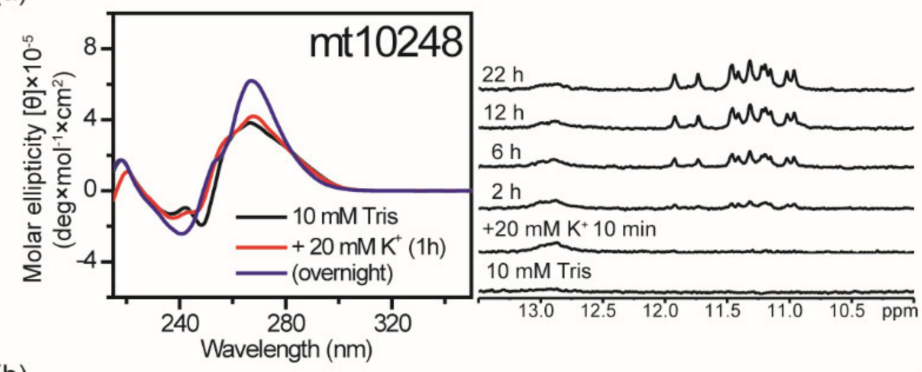

(b)

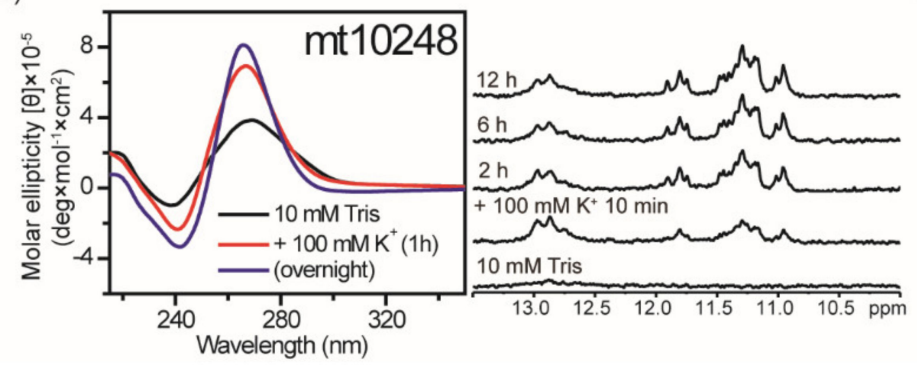

(c)

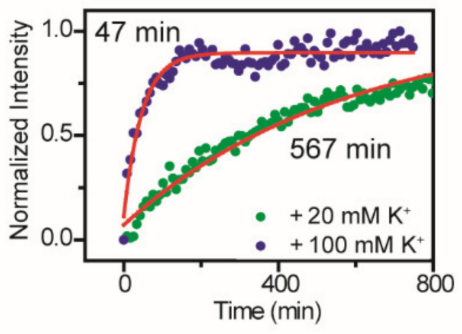

(d)

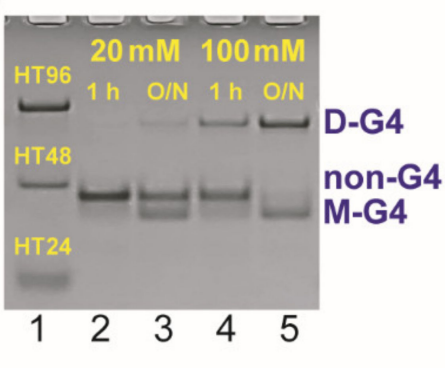

Figure 7. The $\left[\mathrm{K}^{+}\right]$dependent study on the effect of flanking nucleotides on G4 formation of mt10251-FN (mt10248). Time-dependent CD and NMR spectra of mt10248 in $10 \mathrm{mM}$ Tris and after the addition of $20 \mathrm{mM} \mathrm{K}^{+}(\mathbf{a})$ and $100 \mathrm{mM} \mathrm{K}^{+}(\mathbf{b})$. The plots of arising CD signals at $265 \mathrm{~nm}$ of $\mathrm{mt} 10248$ fitted with single exponential after the addition of $20 \mathrm{mM} \mathrm{K}^{+}$and $100 \mathrm{mM} \mathrm{K}^{+}$(c). PAGE assays of marker bands of HT24 $\left(\mathrm{T}_{2} \mathrm{AG}_{3}\right)_{4}, \mathrm{HT} 48\left(\mathrm{~T}_{2} \mathrm{AG}_{3}\right)_{8}$, and HT96 $\left(\mathrm{T}_{2} \mathrm{AG}_{3}\right)_{16}$ and mt10248 after $1 \mathrm{~h}$ and $\mathrm{O} / \mathrm{N}$ addition of $20 \mathrm{mM} \mathrm{K}^{+}$and $100 \mathrm{mM} \mathrm{K}^{+}(\mathbf{d})$. The same DNA concentration of $100 \mu \mathrm{M}$ was used in the experiments of $\mathrm{CD}, \mathrm{NMR}$ and PAGE of this work.

\subsection{Effect of $\mathrm{K}^{+}$Concentration on Thermal Stability of $\left(\mathrm{G}_{3} \mathrm{HG}_{3} \mathrm{~N}_{m} \mathrm{G}_{3} \mathrm{HG}_{3}\right) \mathrm{G} 4$ Structures}

We further measured melting temperature for G4 unfolding of these sequences after the addition of $\mathrm{K}^{+}$overnight without annealed to examine the effect of $\mathrm{K}^{+}$concentration on monomeric and dimeric G4 structures. Figure 8a shows CD melting curves at $265 \mathrm{~nm}$ for T16T-FN, T10T-FN, T4T-FN, T2T-FN, and TTT-FN in $100 \mathrm{mM} \mathrm{K}^{+}$solution. Since the thermal melting curve may not be at thermodynamic equilibrium, such melting temperatures are named apparent melting temperatures [31] or transition temperatures [32]. The apparent melting temperature, $\operatorname{Tm}(\mathrm{A})$, was obtained from the first derivative of the melting curve and was listed in Table 1 . Figure $8 \mathrm{~b}$ shows plots of $\operatorname{Tm}(\mathrm{A})$ as a function of middle loop length of both $\left(\mathrm{G}_{3} \mathrm{HG}_{3} \mathrm{~N}_{\mathrm{m}} \mathrm{G}_{3} \mathrm{HG}_{3}\right)$ and $\left(\mathrm{G}_{3} \mathrm{HG}_{3} \mathrm{~N}_{\mathrm{m}} \mathrm{G}_{3} \mathrm{HG}_{3}\right)$-FN sequences after the addition of $20 \mathrm{mM} \mathrm{K}^{+}$and $100 \mathrm{mM} \mathrm{K}^{+}$overnight. Consistent with the previous finding [7-9], Tm(A) generally decreases as the middle loop length increases up to 10 bases. In addition, the single base loop with thymine has higher $\operatorname{Tm}(\mathrm{A})$ than the single base loop with adenine.

The Tm normally increases as the $\mathrm{K}^{+}$concentration increases, indicating that the G4 structure is more stable at high $\mathrm{K}^{+}$concentration. Previously, a linear plot of $\mathrm{Tm}$ vs $\ln \left[\mathrm{K}^{+}\right]$with a slope about $\sim 7.0$ was obtained for a number of G4 structures [6,33]. Here we measured Tm(A) of T16T, T10T, T16T-FN, and T10T-FN together with native G-rich sequences of PIG4-d(FN) and mt10248 as a function of $\mathrm{K}^{+}$ concentration to compare the effect of $\mathrm{K}^{+}$concentration on monomeric and dimeric G4 structures. Figure $8 \mathrm{c}$ shows the CD melting curves of T10T in $20 \mathrm{mM}, 50 \mathrm{mM}, 70 \mathrm{mM}$, and $100 \mathrm{mM} \mathrm{K}^{+}$solution. Figure $8 \mathrm{~d}$ shows the plots of $\mathrm{Tm}(\mathrm{A})$ of these six sequences as a function of $\ln \left[\mathrm{K}^{+}\right]$with the linear regression fits. Here the slope near 9.0 was obtained for dimeric G4 structures of T16T, T10T, and PIG4-d(FN), while the slope near 6.0 was obtained for monomeric G4 structures of T16T-FN, T10T-FN, and $\mathrm{mt10248.} \mathrm{It} \mathrm{is} \mathrm{suggested} \mathrm{that} \mathrm{high} \mathrm{K}^{+}$concentration generally plays a more crucial role in dimeric G4 formation. 
(a)

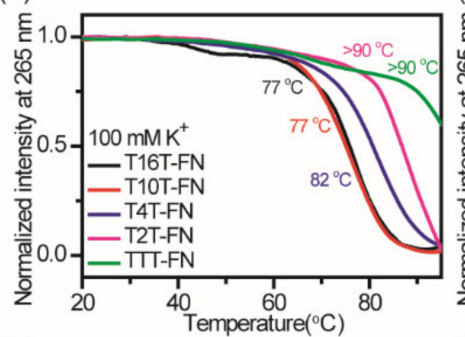

(b)

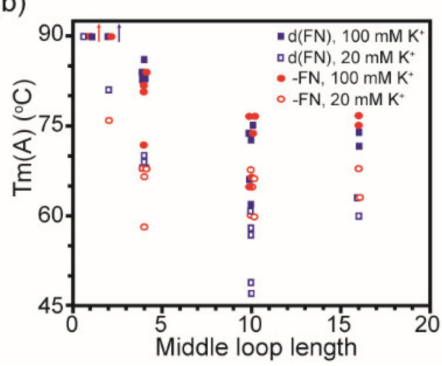

(c)

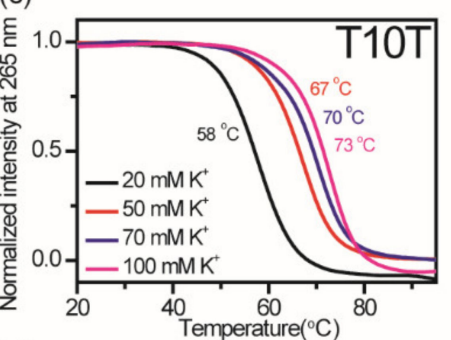

(d)

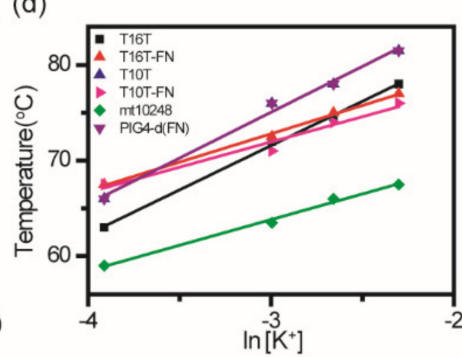

(e)

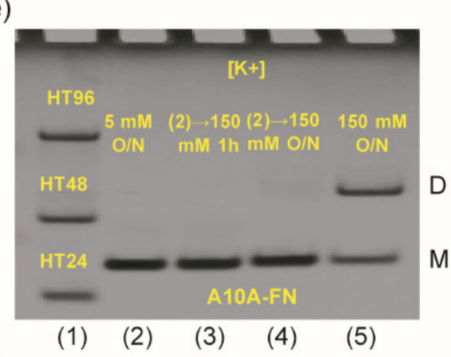

(f)

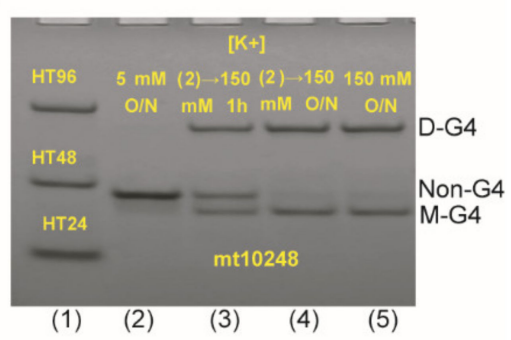

Figure 8. The effect of $\mathrm{K}^{+}$concentration on thermal stability of $\left(\mathrm{G}_{3} \mathrm{HG}_{3} \mathrm{~N}_{\mathrm{m}} \mathrm{G}_{3} \mathrm{HG}_{3}\right) \mathrm{G} 4$ structures. (a) CD melting curves of T16T-FN, T10T-FN, T4T-FN T2T-FN, and TTT-FN after the addition of $100 \mathrm{mM}$ $\mathrm{K}^{+}$overnight. (b) The plots of $\mathrm{Tm}(\mathrm{A})$ as a function of middle loop length of both $\left(\mathrm{G}_{3} \mathrm{TG}_{3} \mathrm{~N}_{\mathrm{m}} \mathrm{G}_{3} \mathrm{TG}_{3}\right)$ and $\left(\mathrm{G}_{3} \mathrm{TG}_{3} \mathrm{~N}_{\mathrm{m}} \mathrm{G}_{3} \mathrm{TG}_{3}\right)-\mathrm{FN}$ sequences after the addition of $20 \mathrm{mM} \mathrm{K}^{+}$and $100 \mathrm{mM} \mathrm{K}^{+}$overnight. (c) CD melting curves of T10T after the addition of 20, 50, 70, and $100 \mathrm{mM} \mathrm{K}^{+}$overnight. (d) The plots of Tm(A) of T16T, T16T-FN, T10T, T10T-FN, PIG4-d(FN), and mt10248 measured from CD melting as a function of $\ln \left[\mathrm{K}^{+}\right]$with linear regression fits. (e) PAGE assays of marker bands of HT24 $\left(\mathrm{T}_{2} \mathrm{AG}_{3}\right)_{4}$, HT48 $\left(\mathrm{T}_{2} \mathrm{AG}_{3}\right)_{8}$, and $\mathrm{HT} 96\left(\mathrm{~T}_{2} \mathrm{AG}_{3}\right)_{16}$ (lane 1) and A10A-FN after the addition of $5 \mathrm{mM} \mathrm{K}^{+}$overnight (lane 2), followed by the addition of $\mathrm{K}^{+}$to $150 \mathrm{mM}$ for $1 \mathrm{~h}$ (lane 3) and overnight (lane 4), and A10A-FN after the addition of $150 \mathrm{mM} \mathrm{K}^{+}$overnight (lane 5). (f) PAGE assays of marker bands of HT24 $\left(\mathrm{T}_{2} \mathrm{AG}_{3}\right)_{4}$, HT48 $\left(\mathrm{T}_{2} \mathrm{AG}_{3}\right)_{8}$, and HT96 $\left(\mathrm{T}_{2} \mathrm{AG}_{3}\right)_{16}$ (lane 1) and mt10248 after the addition of $5 \mathrm{mM} \mathrm{K}^{+}$overnight (lane 2), followed by the addition of $\mathrm{K}^{+}$to $100 \mathrm{mM}$ for $1 \mathrm{~h}$ (lane 3 ) and overnight (lane 4 ), and $\mathrm{mt10248}$ after the addition of $100 \mathrm{mM} \mathrm{K}^{+}$overnight (lane 5). The same DNA concentration of $100 \mu \mathrm{M}$ was used in the experiments of $\mathrm{CD}$ and PAGE of this work.

Previously, we have studied the effect of $\mathrm{K}^{+}$concentration on structural conversion of intramolecular and intermolecular G4s of bcl2mid [34]. The intramolecular G4 formation of bcl2mid is predominant in $5 \mathrm{mM} \mathrm{K}^{+}$solution and the intermolecular $\mathrm{G} 4$ formation appears in $20 \mathrm{mM} \mathrm{K}^{+}$solution. However, the mix of bcl2mid in $5 \mathrm{mM} \mathrm{K}^{+}$solution with an equal amount of the $150 \mathrm{mM} \mathrm{K}^{+}$solution showed no discernible change from intramolecular G4 structure to intermolecular G4 structure at room temperature, suggesting that the dimeric G4 formation is not due to the aggregation of two monomeric G4 structures. Here the imino proton NMR signals of A10A-FN appreared almost identical in the 10.0-12.5 ppm region in $20 \mathrm{mM} \mathrm{K}^{+}$solution and in $100 \mathrm{mM} \mathrm{K}^{+}$solution. Notably, the PAGE results showed a marked increase in dimeric G4 population of A10A-FN in $100 \mathrm{mM} \mathrm{K}^{+}$than in $20 \mathrm{mM}$ $\mathrm{K}^{+}$solution. Is it possible that high $\mathrm{K}^{+}$concentration promotes the stacking of two monomeric $\mathrm{G} 4$ structures? The Tm(A) of A10A-FN measured from the CD melting curve at $265 \mathrm{~nm}$ is $56{ }^{\circ} \mathrm{C}$ in $5 \mathrm{mM}$ $\mathrm{K}^{+}$solution (data not shown). The PAGE results showed no dimeric formation of A10A-FN in $5 \mathrm{mM}$ $\mathrm{K}^{+}$solution and no discernible change from monomer to dimer after the addition of $\mathrm{K}^{+}$to $150 \mathrm{mM} \mathrm{K}^{+}$ solution overnight (Figure 8e), implying that the dimeric formation is not simply promoted by the stacking of two monomeric G4 structures in $100 \mathrm{mM} \mathrm{K}^{+}$solution.

In contrast, the PAGE results of mt10248 showed very small amounts of monomeric G4 formation and large amounts of non-G4 residues in $5 \mathrm{mM} \mathrm{K}^{+}$solution overnight. The significant decrease in non-G4 residues together with the marked increase of monomeric and dimeric G4 populations are detected after the addition of $\mathrm{K}^{+}$to $100 \mathrm{mM} \mathrm{K}^{+}$solution (Figure 8f). Consistent with PAGE results, the imino proton NMR signals of $\mathrm{mt} 10248$ in $5 \mathrm{mM} \mathrm{K}^{+}$solution are identical as in $20 \mathrm{mM} \mathrm{K}^{+}$solution, and 
the imino proton NMR signals of mt10248 after further addition of $\mathrm{K}^{+}$to $100 \mathrm{mM} \mathrm{K} \mathrm{K}^{+}$solution are the same as in $100 \mathrm{mM} \mathrm{K}^{+}$solution (Figure S6). Since a G-tract is involved in WC hydrogen bond formation characterized by the imino proton signals near 13 ppm, it appears that mt10248 forms interlocked G4 dimer in $100 \mathrm{mM} \mathrm{K}{ }^{+}$solution [35].

\subsection{Ligand Binding to $\left(\mathrm{G}_{3} T \mathrm{G}_{3} \mathrm{~N}_{m} \mathrm{G}_{3} T \mathrm{G}_{3}\right)-F N$ G4 Structures}

Very recently, Liu et al. [26] reported ligand binding of BMVC to match the G-quartet for an optimal stacking interaction with Pu22 (i.e., T2T-FN). Given that the NMR spectra of T2T-FN and T4T-FN are very similar, it is of interest to examine whether the spectral patterns of T2T-FN and T4T-FN upon interaction with BMVC are also similar. In addition, the imino proton NMR signal in the region of 10.0-12.5 ppm of T10T-FN and T16T-FN are almost identical. Figure 9 shows the imino proton NMR spectra of T2T-FN, T4T-FN, T10T-FN, and T16T-FN upon interaction with 1 equivalent of BMVC in $100 \mathrm{mM} \mathrm{K}^{+}$solution. The results suggested that these $\left(\mathrm{G}_{3} \mathrm{TG}_{3} \mathrm{~N}_{\mathrm{m}} \mathrm{G}_{3} \mathrm{TG}_{3}\right)-\mathrm{FN} \mathrm{G} 4$ structures have similar binding sites for BMVC, supporting some structural similarity involved in these sequences. Similar NMR results were also detected in T2T-FN and T4T-FN upon interaction with 1 equivalent of BRACO-19 in $100 \mathrm{mM} \mathrm{K}^{+}$solution (Figure S7). Such similarity is crucial for drug development to target G4 structures.
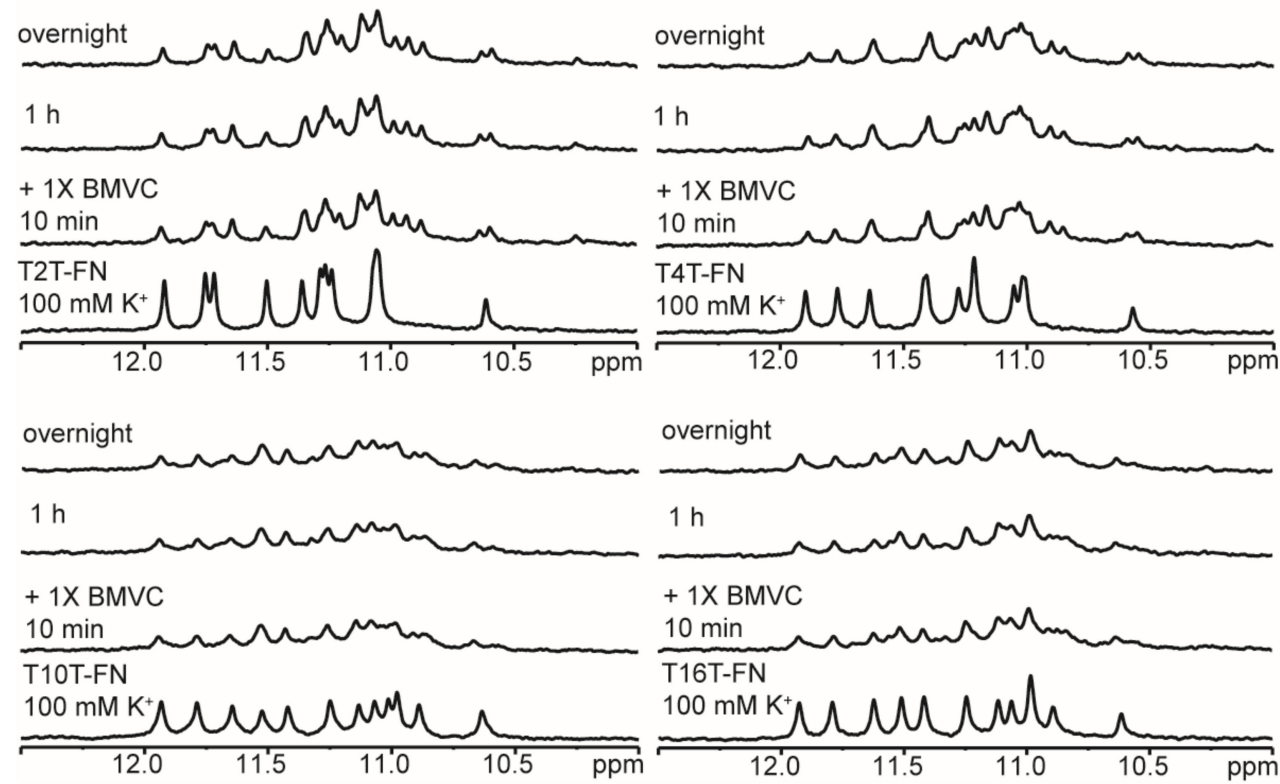

Figure 9. Ligand binding of $B M V C$ to $\left(\mathrm{G}_{3} \mathrm{TG}_{3} \mathrm{~N}_{\mathrm{m}} \mathrm{G}_{3} \mathrm{TG}_{3}\right)-\mathrm{FN} \mathrm{G} 4$ structures. Imino proton NMR spectra of T2T-FN, T4T-FN, T10T-FN, and T16T-FN in $100 \mathrm{mM} \mathrm{K}^{+}$solution and after $10 \mathrm{~min}, 1 \mathrm{~h}$, and overnight addition of 1 eq. BMVC.

\section{Discussion}

A G-rich sequence containing four G-tracts with $\geq 2$ guanines and three loops to connect G-tracts can possibly form a G4 structure. Although there are different types of G4 structures, they all involve the stacking of G-quartets in the formation of G4 structures. Thus, loop sequence plays a major role on their folding topology and thermal stability [4,5]. To deduce rules for predicting the folding pattern and stability of G4s, the effects of loop length and base composition on G4 stability have been extensively studied [6-12]. Most of studies used CD spectra to identify different types of G4 structures and melting to measure melting temperature for characterizing G4 stability [6,7]. For example, CD spectra suggested G-rich sequences $\left(\mathrm{G}_{3} \mathrm{~N}_{\mathrm{i}} \mathrm{G}_{3} \mathrm{~N}_{\mathrm{j}} \mathrm{G}_{3} \mathrm{~N}_{\mathrm{k}} \mathrm{G}_{3}\right)$ with a total loop length of not more than five nucleotides $(i+j+k \leq 5)$ favor parallel $G 4$ structures, while G-rich sequences with a total loop length of more than five nucleotides could form nonparallel G4 structures in $20 \mathrm{mM} \mathrm{K}^{+}$ 
solution [7]. The $\operatorname{Tm}(\mathrm{A})$ of $\left(\mathrm{G}_{3} \mathrm{HG}_{3} \mathrm{~N}_{\mathrm{m}} \mathrm{G}_{3} \mathrm{HG}_{3}\right)$ generally decreases when the length of the middle loop is increased. In addition, the loop base with a single T-base has higher Tm than a single A-base [6-8]. Smargiasso et al. [8] used gel electrophoresis and mass analysis to demonstrate that sequences with short loops, such as $\mathrm{H} 1 \mathrm{H}, \mathrm{H} 2 \mathrm{H}$, and $\mathrm{H} 4 \mathrm{H}$, form predominantly dimers and trimers in $150 \mathrm{mM} \mathrm{K}^{+}$ solution. Particularly, sequences having a single base in their third loop systematically form high-order oligomers. They further proposed that the formation of dimers and trimers are likely due to the stack of parallel intramolecular G4 structures, although some contribution of interlocked dimers cannot be ruled out. Moreover, they reported that monomers are favored when flanking nucleotides are added [8]. Generally, such studies on G4 structures were conducted at low strand concentrations, for example 5 $\mu \mathrm{M}$, which were not sufficient to provide NMR spectra for the comparison of their G4 structures.

\subsection{Structural Diversity and Similarity of $\left(G_{3} H_{G_{3}} N_{m} G_{3} H G_{3}\right)$ Sequences with and without Flanking Nucleotides}

In this work, we have first used CD, NMR, and PAGE to study G4 formation of TTT, T2T, T4T, $\mathrm{T} 10 \mathrm{~T}$, and T16T without flanking nucleotides after the addition of $\mathrm{K}^{+}$. The imino proton NMR spectra of TTT and T2T are similar, but different from T4T and very different from T10T and T16T. The lack of distinct imino proton signals in these NMR spectra is a great challenge for structural analysis. The PAGE results suggest that sequences with long length in the middle loop favor to form dimeric G4 structures, while sequences with short length in the middle loop tend to form high-order G4 structures. Of interest is that PAGE assays show two close bands in TTT, but one band in T2T. Previously, the mass analysis of $5 \mu \mathrm{M} \mathrm{H} 1 \mathrm{H}$ illustrated the presence of dimeric and trimeric G4 structures in $150 \mathrm{mM}$ $\mathrm{K}^{+}$solution [8]. Given that the $100 \mu \mathrm{M}$ TTT may form even high-order G4 structure, we propose two interlocked G4 topologies (Figure 1a). This is because the two close bands in gel migration are unlikely due to the stack of parallel monomeric G4 structures. At present, we are not able to rule out the possible contribution from stack G4 topology (Figure 1b). In addition, the one band, not two bands, in T2T is probably due to the mismatch of TA middle loop to other $\mathrm{T}$ loops.

Here most of the $C D$ spectra of $\left(\mathrm{G}_{3} \mathrm{TG}_{3} \mathrm{~N}_{\mathrm{m}} \mathrm{G}_{3} \mathrm{TG}_{3}\right)$ sequences with or without flanking nucleotides show similar positive band at $265 \mathrm{~nm}$ as a character of parallel G4 structure after the addition of $\mathrm{K}^{+}$. The PAGE results clearly indicate that those sequences without flanking nucleotides favor to form multimeric G4 structures, while those sequences with flanking nucleotides tend to form monomeric G4 structures. Indeed, Rachwal et al. [33] previously found a monomeric parallel G4 formation of $\left(\mathrm{TG}_{3} \mathrm{TG}_{3} \mathrm{TG}_{3} \mathrm{TG}_{3} \mathrm{~T}\right.$ ) in $\mathrm{K}^{+}$solution (Figure 1c). We consider that this monomeric $\mathrm{G} 4$ structure is also the G4 structure formed by TTT-FN in this work. In addition, Ambrus et al. [25] have determined the monomeric G4 structure of Pu22 (T2T-FN) in $\mathrm{K}^{+}$solution (Figure 1c). This finding is important since monomeric G4 structure is more biologically relevant. In addition, their imino proton NMR spectra allow us to examine the effects of loop composition and flanking nucleotides on their G4 structures. Different NMR spectra due to the change of base composition in the middle loop indicate that loop composition plays an important role in determining their G4 structures. Surprisingly, we found that the imino proton NMR spectral patterns of T10T-FN, A10A-FN, C10C-FN are almost identical, and the imino proton NMR spectral patterns of T4T-FN, A4A-FN, and C4C-FN are also very similar in $20 \mathrm{mM} \mathrm{K}^{+}$solution, implying that the change of a single base $\mathrm{T}, \mathrm{A}$, and $\mathrm{C}$ in loop 1 and loop 3 in $\left(\mathrm{G}_{3} \mathrm{HG}_{3} \mathrm{~N}_{\mathrm{m}} \mathrm{G}_{3} \mathrm{HG}_{3}\right)-\mathrm{FN}$ sequences with the same middle loop has no appreciable effect on their monomeric G4 structures.

\subsection{Effects of Intramolecular and Intermolecular WC Hydrogen Bonds on G4 Structures}

Recently, Lim and Phan [30] used NMR to investigate a number of quadruplex-duplex mixed structures. Particularly, the imino proton NMR spectrum of a construct $\mathrm{V}$ sequence, $5^{\prime}-\mathrm{TTG}_{3} \mathrm{TG}_{3} \mathrm{CGC}$ GAAGCATTCGCGG $\mathrm{TG}_{3} \mathrm{~T}-3^{\prime}$, showed two peaks near $13.5 \mathrm{ppm}$ for $\mathrm{T}(19)$ and $\mathrm{T}(20)$, three peaks near 13 ppm for $G(11), G(13)$, and $G(22)$, and twelve peaks for $G 4$ signals, such imino proton NMR signals were valuable to propose a hybrid quadruplex-duplex structure with a hairpin duplex formed within the long middle loop of monomeric G4 structure (Figure 1d) [30]. Onel et al. reported 
two similar quadruplex-duplex mixed structures (Figure 1d,e) coexisted in a native PIG4 sequence located at the upstream of the human BCL2 gene P1 promoter [29]. In addition, Krauss et al. [36] have introduced an 8-mer, d-(TAACGCTA), complementary to the $3^{\prime}$ end of a long sequence, $5^{\prime}-\mathrm{G}_{3} \mathrm{TG}_{3} \mathrm{TG}_{3} \mathrm{TG}_{3} \mathrm{TTAGCGTTA}-3^{\prime}$, for revealing in detail the quadruplex-duplex interface using $X$-ray crystallography. They found that such interface could provide a stable pocket for the binding of selective molecules. Better understanding of such quadruplex-duplex junction may be important in biological and therapeutic implications [15] and in DNA nanotechnology [37].

It is noted that the middle loop in T16T and T16T-FN may form either intramolecular or intermolecular hydrogen bonds in $10 \mathrm{mM}$ Tris. After the addition of $\mathrm{K}^{+}$, T16T forms dimeric G4 structure and T16T-FN adopts into monomeric G4 structure. Considering that both T16T-FN and construct V sequence [30] contain a duplex hairpin in the middle loop, it is very likely that T16T-FN can also form a monomeric quadruplex-duplex structure (Figure 1d). Since the imino proton signals in the region of 12.5-14.0 ppm of T16T and T16T-FN are almost identical, such signals are due to intramolecular WC hydrogen bond. Thus, two possible topologies of dimeric quadruplex-duplex junction are proposed for T16T (Figure 1f). Here our results indicate that intramolecular hydrogen bond is a prior formation than intermolecular hydrogen bond in T16T-FN.

Although the middle loop in T10T may form intermolecular WC hydrogen bonds, the imino proton NMR signals of T10T due to WC hydrogen bonds are not detected after the addition of $\mathrm{K}^{+}$. Here two possible topologies of dimeric G4 structures are proposed for T10T (Figure 1g). Of interest is that the imino proton NMR signals in the region of 12.5-14.0 ppm of T10T-FN are clearly detected in $100 \mathrm{mM} \mathrm{K}^{+}$solution, but not detected in $20 \mathrm{mM} \mathrm{K}^{+}$solution. Notably, the imino proton NMR signals in the region of 10.0-12.5 ppm are almost identical in $20 \mathrm{mM} \mathrm{K}^{+}$and in $100 \mathrm{mM} \mathrm{K}^{+}$solution. Such similar spectral features are also observed in A10A-FN and C10C-FN. The imino proton NMR signals due to WC hydrogen bonds in the region of 12.5-14 ppm of T10T-FN and T16T-FN are different. According to the study of quadruplex-duplex junction by Lim and Phan [30], we can assign the imino proton NMR signal detected near 13.5 ppm to T(13) in T10T-FN. Such signal cannot be due to intramolecular WC hydrogen bond, instead intermolecular hydrogen bond of T10T-FN. Thus, the weak imino proton signals near 13.5 ppm corresponding to a weak band in PAGE is likely due to a dimeric duplex of T10T-FN. In addition, we propose that T10T-FN forms a monomeric G4 structure (Figure 1c).

Considering the formation of intramolecular hydrogen bonds in T16T-FN and intermolecular hydrogen bonds in T10T-FN, it is surprised that the imino proton signals of T10T-FN and T16T-FN in the region of 10.0-12.5 ppm are almost identical for monomeric G4 structures. For comparison, we further study the NMR spectra of T10T-1-FN and A10A-1-FN, a single base substitution of A-base by T-base in the middle loop of $\mathrm{H} 10 \mathrm{H}-\mathrm{FN}$. Indeed, the NMR results show no imino proton signal in the region of 12.5-14 ppm, but almost identical imino proton signals in the region of 10.0-12.5 ppm to that of T10T-FN and A10A-FN in $100 \mathrm{mM} \mathrm{K}^{+}$solution (Figure S8). They also form a monomeric G4 structure (Figure 1c). Here our results illustrate that such different WC hydrogen bonds play no appreciable change in their monomeric G4 structures.

\subsection{Effects of Potassium Concentration on $\left(G_{3} H G_{3} N_{m} G_{3} H G_{3}\right)-F N$ G4 Structures}

The importance of $\mathrm{K}^{+}$concentration to the G-rich sequences is not only to stabilize the G4 structure but also to cause changes in structural populations and polymorphism. Previously, we found that mt10251 sequence without flanking nucleotides can form intramolecular WC hydrogen bonds in $10 \mathrm{mM}$ Tris. After the addition of $20 \mathrm{mM} \mathrm{K}^{+}$, the intermolecular $\mathrm{G} 4$ formation was much more dominated than the intramolecular G4 formation [24]. Here NMR results show that the intramolecular WC hydrogen bonds in a native mt10248 sequence is negligible in $10 \mathrm{mM}$ Tris. After the addition of $20 \mathrm{mM} \mathrm{K}^{+}$, NMR results show that the hairpin formation is prior to the G4 formation. Notably, PAGE results show that only a small portion of mt10248 form monomeric G4 structures in $20 \mathrm{mM} \mathrm{K}^{+}$solution, however, more dimeric G4 population than monomeric G4 population is detected in $100 \mathrm{mM} \mathrm{K}^{+}$ solution. Of importance is that the arising time of G4 formation characterized by the $265 \mathrm{~nm}$ CD signal 
is much shorter after the addition of $100 \mathrm{mM} \mathrm{K}^{+}$than the addition of $20 \mathrm{mM} \mathrm{K}^{+}$, implying that high $\mathrm{K}^{+}$ concentrations kinetically favor to dimeric G4 formation. In addition, PAGE results show that a large portion of non-G4 residues are detected in $20 \mathrm{mM} \mathrm{K}^{+}$solution but are almost negligible in $100 \mathrm{mM}$ $\mathrm{K}^{+}$solution. The study of numerous single-base mutants of 10251 indicated that the third G-tract is involved in hairpin formation with three consecutive C-bases $[24,35]$. Considering similar population of monomeric G4 formation of 10248 in $20 \mathrm{mM} \mathrm{K}^{+}$and in $100 \mathrm{mM} \mathrm{K}^{+}$solution, such hairpin formation must be unfolded for monomeric G4 formation (Figure 1c).

The PAGE assays of A10A-FN prepared in $5 \mathrm{mM} \mathrm{K}^{+}$solution overnight and then adding more $\mathrm{K}^{+}$to $150 \mathrm{mM} \mathrm{K}^{+}$solution show no dimeric formation, which is very different from the preparation of A10A-FN in $100 \mathrm{mM} \mathrm{K}^{+}$solution. In contrast, the PAGE assays of $\mathrm{mt} 10248$ prepared in $5 \mathrm{mM}$ $\mathrm{K}^{+}$solution overnight and then adding more $\mathrm{K}^{+}$to $100 \mathrm{mM} \mathrm{K}^{+}$solution show both monomeric and dimeric formation, which is almost the same as the preparation of mt10248 in $100 \mathrm{mM} \mathrm{K}^{+}$solution. This is because only a small portion of $\mathrm{mt} 10248$ form monomeric $\mathrm{G} 4$ structure in $5 \mathrm{mM} \mathrm{K}^{+}$solution and a large portion of residues favor to form dimeric $\mathrm{G} 4$ structure after the addition of $\mathrm{K}^{+}$to $100 \mathrm{mM} \mathrm{K}$. However, most of A10A-FN form monomeric G4 structure in $5 \mathrm{mM} \mathrm{K}^{+}$solution. As a result, there is no dimeric formation after the addition of $\mathrm{K}^{+}$to $150 \mathrm{mM} \mathrm{K} \mathrm{K}^{+}$solution. Apparently, significant increase in dimeric population of A10A-FN in $100 \mathrm{mM} \mathrm{K}^{+}$solution is not due to aggregation of monomeric G4 structure.

Considering the earlier detection of hairpin structure in the NMR spectra of mt10248 after the addition of $20 \mathrm{mM} \mathrm{K}^{+}$, the formation of WC hydrogen bond is kinetically prior to the formation of Hoogsteen hydrogen bond. However, the slowly decrease of imino proton signals near $13.5 \mathrm{ppm}$ together with the gradual increase of imino proton signals in the region of 10-12.5 ppm as a function of time suggests that the hairpin unfolding is faster than G4 unfolding, implying that monomeric G4 structure is more thermal stable than the hairpin structure [38,39]. Indeed, the $\operatorname{Tm}(\mathrm{A})$ for hairpin structure is $54.4 \pm 0.5^{\circ} \mathrm{C}$ for hairpin structure of a mt10251 mutant [35] and $58 \pm 1.06{ }^{\circ} \mathrm{C}$ for monomeric G4 structure of 10248 in $20 \mathrm{mM} \mathrm{K}^{+}$solution. We further found more population of dimeric G4 formation than monomeric G4 formation of mt10248 in $100 \mathrm{mM} \mathrm{K}^{+}$solution, implying that high $\mathrm{K}^{+}$concentration favors the formation of dimeric than monomeric G4 structures. Previously, we found that the possible formation of dimeric quadruplex-duplex structure of mt10251 (Figure 1h) can be ignored [35]. Thus, two possible topologies of dimeric G4 structures without hairpin formation are proposed for T10T (Figure 1g). Consistent with PAGE results, the imino proton signals near $13.5 \mathrm{ppm}$ is likely due to a monomeric hairpin structure, the fine signals and the broad signals overlapped in the region of 10-12.5 ppm are due to monomeric and dimeric G4 structures, respectively.

\subsection{Implication to Native Sequences}

The findings that the $\left(\mathrm{G}_{3} \mathrm{HG}_{3} \mathrm{~N}_{\mathrm{m}} \mathrm{G}_{3} \mathrm{HG}_{3}\right)$ sequences without four consecutive G-bases favor to form multimeric $\mathrm{G} 4$ structures and the $\left(\mathrm{G}_{3} \mathrm{HG}_{3} \mathrm{~N}_{\mathrm{m}} \mathrm{G}_{3} \mathrm{HG}_{3}\right)-\mathrm{FN}$ sequences tend to form monomeric G4 structures can be applied to native G-rich sequences, such as mt10248 [24], Pu22 [25], GTERT [28], and PIG4 [29]. In addition, conformational change from a monomeric G4 formation to a multimeric G4 formation is detected in T4T and T4T-3 after the addition of $100 \mathrm{mM} \mathrm{K}{ }^{+}$. Such conformational change is also observed in GTERT-d(FN) after the addition of $100 \mathrm{mM} \mathrm{K}{ }^{+}$. Notably, they all show spectral change from a major $265 \mathrm{~nm}$ band together with a minor $290 \mathrm{~nm}$ band to a single $265 \mathrm{~nm}$ band after the addition of $100 \mathrm{mM} \mathrm{K}{ }^{+}$from $1 \mathrm{~h}$ to overnight. The detection of $290 \mathrm{~nm} \mathrm{CD}$ band is normally due to nonparallel G4 formation. The absence of the $290 \mathrm{~nm}$ band in the final state suggests that this nonparallel G4 structure is an intermediate state. The PAGE results indicate that they all involve conformational change from monomeric G4 to multimeric G4 structures. It is important to determine their initial and final G4 structures. In addition, the similarity of such conformational change from monomeric to multimeric G4 structures deserve further study. The study of underlying mechanism of conformational change is not only important to explore the complexity and beauty of DNA but also useful to design DNA sequences for nanomaterial application. 
The monomeric G4 structure formed by chl1-d(FN) can be described by four consecutive G bases in the second and the third G-tracts, which can change a single base to two bases in loop 1 and loop 3. Of interest is that the human chl1 sequence forms an unprecedented G4 structure in $\mathrm{K}^{+}$solution [27]. The twelve imino proton NMR signals of chl1 detected in the 11-12 ppm region suggest that it is composed of three G-quartets. Spectral analysis revealed that the first G base is positioned within the central G-quartet. In addition, a V-shaped loop, spanning three G-quartet planes, containing no bridging nucleotides. As a result, the chl1 sequence adopts an unusual $G_{2}-G_{3}-G_{4}-G_{2}$ alignment of G-tracts with four loops of 2, 3, 0, and 1 loop lengths. In this work, we also found similar twelve imino proton NMR signals of chl1-d(FN) in the region of 11-12 ppm. However, the imino proton signal of $\mathrm{G}(11)$ at $11.0 \mathrm{ppm}$ detected in chl1 is not observed in chl1-d(FN). Given that the only difference between chl1 and chl1-d(FN) is the deletion of $\mathrm{T}(19)$ in chl1-d(FN), the G4 structure of chl1-d(FN) deserves further study for the comparison with the G4 structure of chl1.

\subsection{Similarity for the Development of G4 Binding Ligands}

One of the purposes of studying the structural diversity and similarity of G4 structures is to search for common features for the development of G4 binding ligands. Here similar NMR spectral patterns of ligand binding of BMVC to T2T-FN (Pu22), T4T-FN, T10T-FN and T16T-FN suggest the similarity of these $\mathrm{G} 4$ structures, implying that the $\left(\mathrm{G}_{3} \mathrm{HG}_{3} \mathrm{~N}_{\mathrm{m}} \mathrm{G}_{3} \mathrm{HG}_{3}\right)-\mathrm{FN}$ sequences provide similar binding sites for G4 ligands. Further study of ligand binding of BMVC to chl1 and chl1-d(FN) may validate the implication of this work. In addition, similar NMR spectral patterns of ligand binding of BRACO-19 as BMVC to T2T-FN (Pu22) and T4T-FN suggest that these sequences afford the same binding sites for BRACO-19 and BMVC. Previously, we used time-gated fluorescence lifetime imaging microscopy of a BMVC derivative to visualize G4 foci in cells [23]. In addition, we found the decrease in the number of G4 foci in the pretreatment of HeLa cells with BRACO-19, suggesting that BRACO-19 directly binds to G4s in cells [40]. Thus, the study of ligand binding in this work further support our previous work on G4s in cells.

\section{Materials and Methods}

\subsection{DNA Preparation}

DNA oligonucleotides were purchased from Bio Basic (Markham, ON, Canada) and dissolved in $10 \mathrm{mM}$ Tris ( $\mathrm{pH}$ 7.5). They were then subjected to heat-denaturation at $95{ }^{\circ} \mathrm{C}$ for $10 \mathrm{~min}$ and annealed to room temperature at a rate of $1^{\circ} \mathrm{C} / \mathrm{min}$. The annealed oligonucleotides were stored at $4{ }^{\circ} \mathrm{C}$ overnight until the further experiments. The DNA concentrations were determined using a UV-Vis absorption spectrometer (Implen, Munich, Germany).

\subsection{Circular Dichroism (CD)}

CD experiments were conducted using a spectropolarimeter (J-815, Jasco, Tokyo, Japan) with a bandwidth of $2 \mathrm{~nm}$, at a scan speed of $50 \mathrm{~nm} / \mathrm{min}$ and a step resolution of $0.2 \mathrm{~nm}$ over a spectral range of 210-350 nm. The DNA concentration in each sample was $100 \mu \mathrm{M}$ dissolved in $10 \mathrm{mM}$ Tris (pH 7.5), and a stock solution of $3 \mathrm{M} \mathrm{KCl}$ (Sigma-Aldrich, St. Louis, MO, USA) was added to the DNA samples to attain a final $\mathrm{K}^{+}$concentration. The observed signals were baseline subtracted. The melting curves were recorded at $265 \mathrm{~nm}$ from 20 to $95^{\circ} \mathrm{C}$ with a temperature ramping rate of $1{ }^{\circ} \mathrm{C} / \mathrm{min}$ rate controlled by a Peltier thermal coupler chamber (PFD-425S/15, Jasco).

\subsection{Nuclear Magnetic Resonance (NMR) Spectroscopy}

NMR experiments were performed at $25{ }^{\circ} \mathrm{C}$ on an AVIII $500 \mathrm{MHz}$ spectrometer (Bruker, Rheinstetten, Germany) equipped with a Prodigy probehead. One-dimensional (1D) imino proton NMR spectra were recorded using a WATERGATE for water suppression. The strand concentrations 
of the NMR samples were typically $100 \mu \mathrm{M}$, containing $10 \% \mathrm{D}_{2} \mathrm{O}$ in $10 \mathrm{mM}$ Tris (pH 7.5) or specific $\mathrm{K}^{+}$ conditions, with an internal reference of $0.01 \mathrm{mM} 4$,4-dimethyl-4-silapentane-1-sulfonic acid (DSS).

\subsection{Polyacrylamide Gel Electrophoresis (PAGE)}

PAGE was conducted using $20 \%$ polyacrylamide and $0.5 \times$ TBE gels. The DNA concentration for each sample was $100 \mu \mathrm{M}$, that is, the same concentration used for CD and NMR. PAGE was conducted at $150 \mathrm{~V}$ for $3.5 \mathrm{~h}$ at $4{ }^{\circ} \mathrm{C}$. The gels were then photographed under ultraviolet (UV) light at $254 \mathrm{~nm}$ using a digital camera.

\section{Conclusions}

In this work, we used NMR, CD, and PAGE to study the effects of loop length and base composition on G-rich $\left(\mathrm{G}_{3} \mathrm{HG}_{3} \mathrm{~N}_{\mathrm{m}} \mathrm{G}_{3} \mathrm{HG}_{3}\right)$ sequences with and without flanking nucleotides. Since such $\left(\mathrm{G}_{3} \mathrm{HG}_{3} \mathrm{~N}_{\mathrm{m}} \mathrm{G}_{3} \mathrm{HG}_{3}\right)$ configuration could be found in a number of native DNA sequences, we attempted to establish the correlation between model sequences and native sequences to deduce the structural similarity from these sequences. For example, we found that $\left(\mathrm{G}_{3} \mathrm{HG}_{3} \mathrm{~N}_{\mathrm{m}} \mathrm{G}_{3} \mathrm{HG}_{3}\right)$ sequences tend to form multimeric $\mathrm{G} 4$ structures, while $\left(\mathrm{G}_{3} \mathrm{HG}_{3} \mathrm{~N}_{\mathrm{m}} \mathrm{G}_{3} \mathrm{HG}_{3}\right)$-FN sequences favor to form monomeric G4 structures. Such findings can be found in native sequences of mt10248, PU22, GTERT, and PIG4. However, some important findings in model sequences have not been tested in native sequences, such as a single-base difference of $A$, $T$, and $C$ in loop 1 and loop 3 in $\left(\mathrm{G}_{3} \mathrm{HG}_{3} \mathrm{~N}_{\mathrm{m}} \mathrm{G}_{3} \mathrm{HG}_{3}\right)$ sequences showed no obvious change on their G4 structures in this work. We further examined such similarity by using G4 binding ligands, which may be useful for the use and design of G4 ligands in human cancer. Considering a large amounts of G-rich sequences in human gene, this work demonstrates a possible approach to find structural similarity from G-rich sequences.

Supplementary Materials: The following are available online, Figure S1: Kinetic study of G4 formation. The kinetic traces of T10T, T4T-1, and T2T for multimeric G4 formations and T10T-FN, T4T-1-FN, and T2T-FN for monomeric G4 formations by monitoring the $265 \mathrm{~nm} \mathrm{CD}$ signal after the addition of $20 \mathrm{mM} \mathrm{K}^{+}$. Figure S2: The effect of loop base on $\mathrm{G} 4$ formation of $\left(\mathrm{G}_{3} \mathrm{HG}_{3} \mathrm{~N}_{\mathrm{m}} \mathrm{G}_{3} \mathrm{HG}_{3}\right)$ sequences. $\mathrm{CD}$ and NMR spectra of A16T, A10A, and C10C in $10 \mathrm{mM}$ Tris and after $1 \mathrm{~h}$ and overnight addition of $100 \mathrm{mM} \mathrm{K}^{+}$together with their PAGE assays. Figure S3: The effect of loop base on $\mathrm{G} 4$ formation of $\left(\mathrm{G}_{3} \mathrm{HG}_{3} \mathrm{~N}_{\mathrm{m}} \mathrm{G}_{3} \mathrm{HG}_{3}\right)$ sequences with flanking nucleotides. NMR spectra of A16T-FN, A10A-FN and C10C-FN in $10 \mathrm{mM}$ Tris and after $1 \mathrm{~h}$ and overnight addition of $100 \mathrm{mM} \mathrm{K}^{+}$together with their PAGE assays. The same DNA concentration of $100 \mu \mathrm{M}$ was used in the experiments of NMR and PAGE of this work. Figure S4: The effect of loop base on $\mathrm{G} 4$ formation of $\left(\mathrm{G}_{3} \mathrm{HG}_{3} \mathrm{~N}_{4} \mathrm{G}_{3} \mathrm{HG}_{3}\right)$ sequences with flanking nucleotides. NMR spectra of A4A-FN and C4C-FN in $10 \mathrm{mM}$ Tris and after $1 \mathrm{~h}$ and overnight addition of $100 \mathrm{mM}$ $\mathrm{K}^{+}$together with their PAGE assays. The same DNA concentration of $100 \mu \mathrm{M}$ was used in the experiments of NMR and PAGE of this work Figure S5: The effect of loop base on G4 formation of $\left(\mathrm{G}_{3} \mathrm{~T}_{2} \mathrm{G}_{3} \mathrm{~N}_{4} \mathrm{G}_{3} \mathrm{TG}_{3}\right)$ and $\left(G_{3} T_{2} G_{3} N_{4} G_{2} G_{3}\right)$ sequences. $C D$ and NMR spectra of $T_{2} 4 T$ and $T_{2} 4 T_{2}$ in $10 \mathrm{mM}$ Tris and after $1 \mathrm{~h}$ and overnight addition of $100 \mathrm{mM} \mathrm{K}^{+}$together with their PAGE assays after overnight addition of $100 \mathrm{mM} \mathrm{K}^{+}$. The same DNA concentration of $100 \mu \mathrm{M}$ was used in the experiments of CD, NMR and PAGE of this work. Figure S6: The effect of

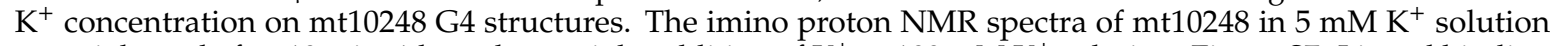
overnight and after $10 \mathrm{~min}, 1 \mathrm{~h}$, and overnight addition of $\mathrm{K}^{+}$to $100 \mathrm{mM} \mathrm{K}^{+}$solution. Figure S7: Ligand binding of BRACO-19 to $\left(\mathrm{G}_{3} \mathrm{TG}_{3} \mathrm{~N}_{\mathrm{m}} \mathrm{G}_{3} \mathrm{TG}_{3}\right)$-FN G4 structures. Imino proton NMR spectra of T2T-FN and T4T-FN in $100 \mathrm{mM} \mathrm{K}^{+}$solution and after $10 \mathrm{~min}, 1 \mathrm{~h}$, and overnight addition of 1 eq. BRACO-19. Figure S8: The effect of loop base on $\mathrm{G} 4$ formation of $\left(\mathrm{G}_{3} \mathrm{HG}_{3} \mathrm{~N}_{10} \mathrm{G}_{3} \mathrm{HG}_{3}\right)$-FN sequences. NMR spectra of A10A-1-FN and T10T-1-FN in $10 \mathrm{mM}$ Tris and after $1 \mathrm{~h}$ and overnight addition of $20 \mathrm{mM} \mathrm{K}^{+}$and $100 \mathrm{mM} \mathrm{K}^{+}$.

Author Contributions: J.L., I.-T.C., T.-A.Y., D.-Y.C., C.-L.W. performed the experiments, analyzed the data and participated in the original draft. T.-C.C. conceived the study, participated in its design and coordination, and finalized the draft of the manuscript. All authors have read and agreed to the published version of the manuscript.

Funding: This work was supported by Academia Sinica (AS-102-TPA07) and the Ministry of Science and Technology [MOST-106-2119-M-001-030-MY3] of the Republic of China.

Acknowledgments: We thank Shing-Jong Huang (Instrumentation Center, National Taiwan University) for assistance in obtaining the Bruker AVIII 500 NMR data. In addition, we thank Ms. Shin-Ya Liu for confirming some of the data.

Conflicts of Interest: The authors declare no conflict of interest. 


\section{References}

1. Huppert, J.L.; Balasubramanian, S. Prevalence of quadruplexes in the human genome. Nucleic Acids Res. 2005, 33, 2908-2916. [CrossRef] [PubMed]

2. Todd, A.K.; Johnston, M.; Neidle, S. Highly prevalent putative quadruplex sequence motifs in human DNA. Nucleic Acids Res. 2005, 33, 2901-2907. [CrossRef] [PubMed]

3. Chambers, V.S.; Marsico, G.; Boutell, J.M.; Antonio, M.D.; Smith, G.P.; Balasubramania, S. High-resolution sequencing of DNA G-quadruplex secondary structures in the human genome. Nat. Biotechnol. 2015, 33, 877-881. [CrossRef] [PubMed]

4. Smirnov, I.; Shafer, R.H. Effect of loop sequence and size on DNA aptamer stability. Biochemistry 2000, 39, 1462-1468. [CrossRef] [PubMed]

5. Hazel, P.; Huppert, J.; Balasubramanian, S.; Neidle, S. Loop-length-dependent folding of G-quadruplexes. J. Am. Chem. Soc. 2004, 126, 16405-16415. [CrossRef]

6. Rachwal, P.; Brown, T.; Fox, K.R. Sequence effects of single base loops in intramolecular quadruplex DNA. FEBS Lett. 2007, 581, 1657-1660. [CrossRef]

7. Bugaut, A.; Balasubramanian, S. A sequence-dependent study of the influence of short loop lengths on the stability and topology of intramolecular DNA G-quadruplexes. Biochemistry 2008, 47, 689-697. [CrossRef]

8. Smargiasso, N.; Rosu, F.; Hsia, W.; Colson, P.; Baker, E.S.; Bowers, M.T.; De Pauw, E.; Gabelica, V. G-quadruplex DNA assemblies: Loop length, cation identity, and multimer formation. J. Am. Chem. Soc. 2008, 130, 10208-10216. [CrossRef]

9. Guedin, A.; Gros, J.; Alberti, P.; Mergny, J.-L. How long is too long? Effects of loop size on G-quadruplex stability. Nucleic Acids Res. 2010, 38, 7858-7868. [CrossRef]

10. Kwok, C.K.; Sherlock, M.E.; Bevilacqua, P.C. Effect of loop sequence and loop length on the intrinsic fluorescence of G-quadruplexes. Biochemistry 2013, 52, 3019-3021. [CrossRef]

11. Piazza, A.; Adrian, M.; Samazan, F.; Heddi, B.; Hamon, F.; Serero, A.; Lopes, J.; Teulade-Fichou, M.-P.; Phan, A.T.; Nicolas, A. Short loop length and high thermal stability determine genomic instability induced by G-quadruplex-forming minisatellites. EMBO J. 2015, 34, 1718-1734. [CrossRef] [PubMed]

12. Cheng, M.; Cheng, Y.; Hao, J.; Jia, G.; Zhou, J.; Mergny, J.-L.; Li, C. Loop permutation affects the topology and stability of G-quadruplexes. Nucleic Acids Res. 2018, 46, 9264-9275. [CrossRef] [PubMed]

13. Mergny, J.L.; Helene, C. G-quadruplex DNA: A target for drug design. Nat. Med. 1998, 4, $1366-1367$. [CrossRef] [PubMed]

14. Siddiqui-Jain, A.; Grand, C.L.; Bearss, D.J.; Hurley, L.H. Direct evidence for a G-quadruplex in a promoter region and its targeting with a small molecule to repress c-MYC transcription. Proc. Natl. Acad. Sci. USA 2002, 99, 11593-11598. [CrossRef] [PubMed]

15. Balasubramanian, S.; Hurley, L.H.; Neidle, S. Targeting G-quadruplexes in gene promoters: A novel anticancer strategy? Nat. Rev. Drug Discov. 2011, 10, 261-275. [CrossRef]

16. Zyner, K.G.; Mulhearn, D.S.; Adhikari, S.; Martinez Cuesta, S.; Di Antonio, M.; Erard, N.; Hannon, G.J.; Tannahill, D.; Balasubramanian, S. Genetic interactions of G-quadruplexes in humans. eLife 2019, 8, e46793. [CrossRef]

17. Zizza, P.; Cingolani, C.; Artuso, S.; Salvati, E.; Rizzo, A.; D’Angelo, C.; Porru, M.; Pagano, B.; Amato, J.; Randazzo, A.; et al. Intragenic G-quadruplex structure formed in the human CD133 and its biological and translational relevance. Nucleic Acids Res. 2016, 44, 1579-1590. [CrossRef]

18. Sutherland, C.; Cui, Y.; Mao, H.; Hurley, L.H. A Mechanosensor Mechanism Controls the G-Quadruplex/i-Motif Molecular Switch in the MYC Promoter NHE III. J. Am. Chem. Soc. 2016, 138, 14138-14151. [CrossRef]

19. Biffi, G.; Tannahill, D.; McCafferty, J.; Balasubramanian, S. Quantitative visualization of DNA G-quadruplex structures in human cells. Nat. Chem. 2013, 5, 182-186. [CrossRef]

20. Biffi, G.; Di Antonio, M.; Tannahill, D.; Balasubramanian, S. Visualization and selective chemical targeting of RNA G-quadruplex structures in the cytoplasm of human cells. Nat. Chem. 2014, 6, 75-80. [CrossRef]

21. Tseng, T.Y.; Chien, C.H.; Chu, J.F.; Huang, W.C.; Lin, M.Y.; Chang, C.C.; Chang, T.C. Fluorescent probe for visualizing guanine-quadruplex DNA by fluorescence lifetime imaging microscopy. J. Biomed. Opt. 2013, 18, 101309. [CrossRef] [PubMed] 
22. Huang, W.C.; Tseng, T.Y.; Chen, Y.T.; Chang, C.C.; Wang, Z.F.; Wang, C.L.; Hsu, T.N.; Li, P.T.; Chen, C.T.; Lin, J.J.; et al. Direct evidence of mitochondrial G-quadruplex DNA by using fluorescent anti-cancer agents. Nucleic Acids Res. 2015, 43, 10102-10113. [CrossRef] [PubMed]

23. Tseng, T.Y.; Chen, W.W.; Chu, I.T.; Wang, C.L.; Chang, C.C.; Lin, M.C.; Lou, P.J.; Chang, T.C. The G-quadruplex fluorescent probe 3, 6-bis (1-methyl-2-vinyl-pyridinium) carbazole diiodide as a biosensor for human cancers. Sci. Rep. 2018, 8, 16082. [CrossRef]

24. Chu, I.-T.; Wu, C.C.; Chang, T.C. G-quadruplex formation by single-base mutation or deletion of mitochondrial DNA sequences. Biochim. Biophys. Acta 2019, 1863, 418-425. [CrossRef] [PubMed]

25. Ambrus, A.; Chen, D.; Dai, J.; Jones, R.A.; Yang, D. Solution structure of the biologically relevant G-quadruplex element in the human c-MYC promoter. Implications for G-quadruplex stabilization. Biochemistry 2005, 44, 2048-2058. [CrossRef]

26. Liu, W.; Lin, C.; Wu, G.; Dai, J.; Chang, T.C.; Yang, D. Structures of 1:1 and 2:1 complexes of BMVC and MYC promoter G-quadruplex reveal a mechanism of ligand conformation adjustment for G4-recognition. Nucleic Acids Res. 2019, 47, 11931-11942. [CrossRef]

27. Kuryavy, V.; Patel, D.J. Solution structure of a unique G-quadruplex scaffold adopted by a guanosine-rich human intronic sequence. Structure 2010, 18, 73-82. [CrossRef]

28. Lim, K.W.; Lacroix, L.; Yue, D.J.E.; Lim, J.K.C.; Lim, J.M.W.; Phan, A.T. Coexistence of two distinct G-quadruplex conformations in the hTERT promoter. J. Am. Chem. Soc. 2010, 132, 12331-12342. [CrossRef]

29. Onel, B.; Carver, M.; Wu, G.; Timonina, D.; Kalarn, S.; Larriva, M.; Yang, D. A new G-quadruplex with hairpin loop immediately upstream of the human BCL2 P1 promoter modulates transcription. J. Am. Chem. Soc. 2016, 138, 2563-2570. [CrossRef]

30. Lim, K.W.; Phan, A.T. Structural basis of DNA quadruplex-duplex junction formation. Angew. Chem. 2013, 52, 8566-8569. [CrossRef]

31. Tran, P.L.T.; De Cian, A.; Gros, J.; Moriyama, R.; Mergny, J.L. Tetramolecular quadruplex stability and assembly. In Quadruplex Nucleic Acids: Topics in Current Chemistry; Chaires, J., Graves, D., Eds.; Springer: Berlin/Heidelberg, Germany, 2012; Volume 330, pp. 243-273.

32. Olsen, C.M.; Lee, H.T.; Marky, L.A. Unfolding thermodynamics of intramolecular G-quadruplexes: Base sequence contributions of the loops. J. Phys. Chem. B 2009, 113, 2587-2595. [CrossRef] [PubMed]

33. Lin, C.T.; Tseng, T.Y.; Wang, Z.F.; Chang, T.C. Structural conversion of intramolecular and intermolecular G-quadruplexes of bcl2mid: The effect of potassium concentration and ion exchange. J. Phys. Chem. B 2011, 115, 2360-2370. [CrossRef] [PubMed]

34. Rachwal, P.A.; Findlow, I.S.; Werner, J.M.; Brown, T.; Fox, K.R. Intramolecular DNA quadruplexes with different arrangements of short and long loops. Nucleic Acids Res. 2007, 35, 4214-4222. [CrossRef] [PubMed]

35. Chu, I.T.; Tseng, T.Y.; Chang, T.C. Comparison and elucidation of structural diversity and variation of G-rich sequences with a single G-base difference. J. Phys. Chem. B 2019, 123, 5423-5431. [CrossRef]

36. Krauss, I.R.; Ramaswamy, S.; Neidle, S.; Haider, S.; Parkinson, G.N. Structural insights into the quadruplex-duplex $3^{\prime}$ interface formed from a telomeric repeat: A potential molecular target. J. Am. Chem. Soc. 2016, 138, 1226-1233. [CrossRef]

37. Yatsunyk, L.A.; Mendoza, O.; Mergny, J.L. "Nano-oddities": Unusual nucleic acid assemblies for DNA-based nanostructures and nanodevices. Acc. Chem. Res. 2014, 47, 1836-1844. [CrossRef]

38. Kuo, M.H.; Wang, Z.F.; Tseng, T.Y.; Li, M.H.; Hsu, S.T.; Lin, J.J.; Chang, T.C. Conformational transition of a hairpin structure to G-quadruplex within the WNT1 gene promoter. J. Am. Chem. Soc. 2015, 137, 210-218. [CrossRef]

39. Wang, Z.F.; Li, M.H.; Chu, I.T.; Winnerdy, F.R.; Phan, A.T.; Chang, T.C. Cytosine epigenetic modification modulates the formation of an unprecedented G4 structure in the WNT1 promoter. Nucleic Acids Res. 2020, 48, 1120-1130. [CrossRef]

40. Tseng, T.Y.; Chu, I.T.; Lin, S.J.; Li, J.; Chang, T.C. Binding of small molecules to G-quadruplex DNA in cells revealed by fluorescence lifetime imaging microscopy of $o$-BMVC foci. Molecules 2019, 24, 35. [CrossRef]

Sample Availability: Sample Availability: Not available.

(C) 2020 by the authors. Licensee MDPI, Basel, Switzerland. This article is an open access article distributed under the terms and conditions of the Creative Commons Attribution (CC BY) license (http://creativecommons.org/licenses/by/4.0/). 